\title{
Liquefaction and Reliquefaction Resistance of Saturated Sand Deposits Treated with Sand Compaction Piles
}

Gowtham Padmanabhan ( $\nabla$ gowtham@eq.iitr.ac.in )

Indian Institute of Technology Roorkee

Ganesh Kumar

Central Building Research Institute

\section{Research Article}

Keywords: Sand compaction pile, Densification, Uniaxial shaking table, Reliquefaction, Seismic response

Posted Date: February 26th, 2021

DOI: https://doi.org/10.21203/rs.3.rs-259542/v1

License: (c) (i) This work is licensed under a Creative Commons Attribution 4.0 International License.

Read Full License 
$7 \quad{ }^{a}$ Department of Earthquake Engineering

8 Indian Institute of Technology Roorkee

$9 \quad$ Roorkee, Uttarakhand - 247667, India

10 Email: gowtham@eq.iitr.ac.in

11

$12 \quad{ }^{\mathbf{b}}$ Scientist and Assistant Professor

13 Geotechnical Engineering Division

14 CSIR - Central Building Research Institute

15 Academy of Scientific and Innovative Research (AcSIR)

16 Roorkee, Uttarakhand - 247667, India

17 Email: ganeshkumar@cbri.res.in

18

19 *corresponding author,

20 Email address: ganeshkumar@cbri.res.in

21 


\section{Abstract}

2 To mitigate liquefaction and its associated soil deformations, ground improvement techniques were adopted in field

3 to reinforce saturated sand deposits. Sand Compaction Pile (SCP) is one such popular proven treatment to improve

4 liquefaction resistance of sandy deposits. Installation of sand compaction piles improves soil density and rigidity

5 which further enhance seismic resistance against liquefaction and this was well evident from past field observations.

6 However, studies involving SCP performance during repeated shaking events were not available/limited. In this

7 study, using 1-g uniaxial shaking table a series of shaking experiments were performed on SCP treated and untreated

8 sand deposits having $40 \%$ and $60 \%$ relative density subjected to repeated incremental acceleration loading

9 conditions(i.e. $0.1 \mathrm{~g}-0.4 \mathrm{~g}$ at $5 \mathrm{~Hz}$ frequency).Parameters such as improvement in soil resistance and relative

10 density, generation and dissipation of excess pore water pressures, maximum observed foundation settlement and

11 soil displacement and variation in cyclic stress ratio were evaluated and compared. Seismic response of liquefiable

12 sand deposits found to be improved significantly due to SCP installation together with occurrence of continuous soil

13 densification under repeated loading. The experimental observations suggested that SCP can perform better even at

14 repeated shaking events.

15

16 Keywords: Sand compaction pile; Densification; Uniaxial shaking table; Reliquefaction; Seismic response.

17 
Soil liquefaction and its associated deformations during earthquake incidence is one of the major threatsto the stability of infra-structures. Also, the occurrence of repeated earthquake events (i.e. Christchurch earthquakes 2010 - 2011; Tohoku, Japan earthquakes 2011; Nepal earthquakes 2015; Kumamoto earthquakes 2016; Indonesian earthquakes 2018, etc.) in the past reported soil reliquefaction events combined with foundation settlement/failures. Though field evidences highlighting the possible reasons for the occurrence of soil liquefaction and reliquefaction; no studies were available in investigating the performance of ground improvement techniques against repeated shaking events. Considering this requirement, performance evaluation of ground treatment technique under repeated shaking events is attempted in this study to verify foundation-soil improvement system interaction under dynamic 9 events.

\section{$11 \quad 1.2$ Studies on Sand Compaction Piles (SCP) in liquefaction mitigation}

12 Sand compaction pile (SCP) improvement system is a most popular and widely adopted ground improvement 13 technique for improving seismic response of liquefiable deposits. The assessment studies carried out by Tokimatsu 14 et al. (1990) on the performance of 3016 SCP's inferred that, the technique is effective in mitigating liquefaction 15 phenomenon in the site at Tokyo bay, Japan. Similar observations in seismic resistance and the improvement in SPT 16 penetration after SCP treatment were reported by Okamura et al. (2003) for three different liquefiable fields in

17 Japan. The authors reported that, irrespective of area replacement ratio and method of construction, SCP system is found more effective in minimizing liquefaction potential. Through field investigations and undrained cyclic shear tests, Okamura et al. (2006) found that, the liquefaction resistance of SCP treated deposits increased considerably for a slight reduction in degree of saturation irrespective of sand density. Factors such as grain size, pile depth, replacement ratio and distance from the sand pile also influence the saturation of treated sand deposits.

22 Yamada et al. (2010) reported, occurrence of liquefaction and reliquefaction phenomenon during the historic 2011

23 Tohoku, Japan earthquake which witnessed main-shock and successive aftershock events. Severe damages were incurred to the infra-structures due to repeated strong earthquake events. However, the sites where SCP installed 25 showed improvement in soil resistance against liquefaction and reliquefaction. Further, Harada and Ohbayashi, 26 (2017) also investigated the potential of SCP system prior earthquake events and events during 2003 Tokachi-Oki

27 earthquake and 2004 Nemuro Hanto-Oki earthquake, and found limited soil liquefaction and reliquefaction occurrence in SCP treated areas compared to untreated deposits. 
3 Instances of repeated earthquakes events (e.g., the main shock and foreshocks/aftershocks) induces occurrence of

4 soil reliquefaction i.e. soil liquefied more than once (Tohoku, Japan earthquake 2011).To understand liquefaction

5 and reliquefaction phenomenon and to investigate the factors influencing reliquefaction behaviour, extensive

6 experimental, analytical and numerical studies were performed in the past by various researchers (Oda et al. 2001;

7 Yamada et al. 2010;Dobry et al. 2015; Fallahzadeh et al. 2019; Darby et al. 2019 among others).Ye et al. (2007)

8 through experimental and numerical investigations observed, quicker dissipation of excessive pore water pressure

9 (EPWP), when the model ground subjected to repeated shaking events, and in turn induces particle reorientation in

10 the ground profile. Further, soil reliquefaction was reported in the subsequent loading despite its improvement in

11 relative density occurred due to previous loading. Similarly, Ha et al. (2011) performed repeated acceleration

12 loading on soils having differing gradation characteristics and observed that redistribution of sand deposits under

13 repeated shaking was greatly influenced by grain characteristics. Further, Ha et al. (2011) stated, once initial sand

14 fabric got destroyed during the first liquefaction event, then void ratio becomes a reliable parameter than relative

15 density in assessing reliquefaction resistance for any sand deposits. Using centrifuge experiments, El-Sekelly et al.

16 (2016) discussed the effect of pre-shaking on liquefiable deposits and compared the test results with field

17 observations. They concluded that, intensity of successive seismic shaking plays a vital role in initiating

18 reliquefaction and also influences the beneficial effect of pre-shaking in generating excess pore pressures. Studies

19 related to the effect of reliquefaction at mesoscopic level were carried by Ye et al. (2018) through 1-g shaking table

20 experiments. The experiments were performed with successive identical input motions with varying shaking

21 duration. The study revealed that, non-uniformity soil deposition resulted in reduction in reliquefaction resistance

22 despite of improvement in relative density similar to Ye et al, 2007.

23

$24 \quad 1.4$ Scope

25 This study discusses the performance of Sand Compaction Pile (SCP) system in mitigating liquefaction and

26 reliquefaction phenomenon. To assess the performance of ground improvement system, 1-guniaxial shaking table

27 experiments were carried on untreated and SCP treated saturated ground. For testing, saturated ground having 40\%

28 and $60 \%$ density was prepared and subjected to repeated shaking events(i.e. $0.1 \mathrm{~g}, 0.2 \mathrm{~g}, 0.3 \mathrm{~g}$ and $0.4 \mathrm{~g}$ at $5 \mathrm{~Hz}$ 
frequency representing low to high intensity shaking events). To evaluate SCP performance, four SCP's having

2 diameter $111 \mathrm{~mm}$ and length $600 \mathrm{~mm}$ were installed in square pattern with an improvement ratio of $3 \%$ and tested at

3 repeated shaking events. The beneficial effect of the selected improvement system was evaluated in terms of pore

4 water pressure response at different depths, improvement in soil resistance and ground density, foundation

5 settlement, soil displacement assessment and estimated cyclic stress ratio parameters. Finally, the effect of SCP

6 induced ground densification mechanism in improving liquefaction and reliquefaction resistance is discussed.

7

\section{2. Material and apparatus}

\section{$9 \quad 2.1$ Sand}

10 Locally available sand from Solani river bed (Roorkee, India) is used for conducting experimental investigations.

11 The selected soil region lies in seismic zone IV as per Indian standard codal provisions (IS 1893 (Part I) - 2016).

12 From grain size distribution, the Solani sand is found to be poorly graded (SP) (IS 2720 Part 4 - 1985) and lies

13 within the range of liquefiable soils as suggested by (Tsuchida 1970; Xenaki and Asthanapoulos, 2003). The grain

14 size distribution curve and index properties of solani sand were given in Fig. 1 and Table 1 respectively.

\section{$16 \quad 2.2$ 1-g shake table}

17 The laboratory experiments were performed on a uniaxial 1-g shaking table available at Geotechnical engineering 18 division, CSIR - CBRI, Roorkee, India. The dimensions of the shake table unit are $2 \mathrm{~m} \times 2 \mathrm{~m}$ having $3 \mathrm{~T}$ capacity.

19 The horizontal movement of the table can be formed using a servo-hydraulic actuator attached to the shake table.

20 The maximum peak velocity, maximum stroke length, operating frequency and acceleration range are $2 \mathrm{~m} / \mathrm{s}, 80 \mathrm{~mm}$,

21 0.01-50 Hz and 0.001-1 g, respectively. The acceleration and dynamic load frequency can be selected as per testing

22 conditions using digital controlled data acquisition system.

23

\section{$24 \quad 2.3$ Digital static cone penetrometer}

25 Digital static cone penetrometer (DCPT) was used for estimating the relative density of prepared ground bed. The 26 penetrometer consists of a driving cone having $60^{\circ}$ angle which is connected to an extension rod and having digital

27 display unit at the end. Using digital display unit, the penetration resistance at different depth is measured. For 28 penetration resistance measurement, the penetrometer is pushed continuously in to the prepared ground at the rate of 
$10 \mathrm{~mm} / \mathrm{s}$ to 20mm/s (IS 4968 (Part -III) - 1976 and ASTM D3441 - 16). From the obtained cone penetration resistance, relative density of the sand deposit was estimated.

4 3. Experimental procedure

\section{$5 \quad 3.1$ Sand-bed preparation}

6 A rigid transparent perspex model tank of dimensions $1.4 \mathrm{~m} \times 1 \mathrm{~m} \times 1 \mathrm{~m}$ was fabricated and used for shaking table

7 experiments. To minimize boundary effects, $50 \mathrm{~mm}$ thick polyurethane foam was attached to both sides of tank in 8 shaking direction (Ye et al. 2018; Padmanabhan and Shanmugam, 2020). The bottom surface of the model tank was 9 made rough by sand blasting technique for simulating real field conditions. Generally, the liquefaction response of 10 the saturated sand deposits is highly influenced by the method of sample preparation (Mullins et al. 1977; Tatsuoka 11 et al. 1986). Hence, based on literature studies, wet sedimentation method was adopted for sample preparation since 12 this method proven to be effective in achieving uniform relative density and for simulating natural sand deposition 13 behaviour (Ye et al. 2007; Hamayoon et al. 2016; Bahmanpour et al. 2019).

14 For experimental studies, saturated sand bed having $600 \mathrm{~mm}$ depth was prepared with $40 \%$ and $60 \%$ density. The 15 quantity of sand and water required to achieve $40 \%$ and $60 \%$ ground density is estimated prior and collected. The 16 calculation and preparation procedure were same as discussed by Padmanabhan and Shanmugam (2020). The 17 ground bed was divided in to three layers to achieve uniformity in density. Water was filled initially inside the tank 18 for the calculated first layer. Followed by water, sand was then poured into the tank. To facilitate the free fall and for 19 uniform distribution, an adjustable conical hopper with a $60^{\circ}$ inverted cone at bottom is exclusively fabricated and 20 used. The height at which the sand grains to be poured to achieve relative density is evaluated as per IS 2720 (Part 21 XIV) - 2006. Thus using wet sedimentation technique, the ground having $40 \%$ and $60 \%$ density simulating

22 liquefiable saturated sand deposit was prepared. The prepared sand bed was left undisturbed for 24 hours to obtain 23 uniform saturation and deposition. To monitor pore pressure generation and dissipation, glass tube piezometers were 24 used for the study. The glass tube piezometers were placed in middle of the ground bed at $0.2 \mathrm{~m}(\mathrm{~B})$ and $0.4 \mathrm{~m}(\mathrm{~T})$ 25 height from base of the tank.

26

\section{$27 \quad 3.2$ Installation of Sand Compaction Piles}


To simulate real field conditions, Sand compaction piles (SCPs) were installed into prepared sand bed similar to the procedure adopted in field (Harada and Ohbayashi, 2017). Polyvinyl chloride (PVC) pipe was used as a casing pipe for constructing SCP system. A total of four SCPs with a diameter of $111 \mathrm{~mm}$ and $600 \mathrm{~mm}$ height (improvement ratio of $3 \%$ ), were installed in square pattern with $\mathrm{c} / \mathrm{c}$ of $450 \mathrm{~mm}$ in the sequential manner. The improvement ratio was defined as the total sectional area of sand compaction pile (improved area) to the total area of the model tank (Kitazume, 2005). Square pattern installation was adopted in this study, as it found effective in improving the relative density of sand deposits for replacement/improvement ratio less than 13\% (Hossain et al. 2020). Stages of SCP installation is shown in Fig. 2and the installation procedure is as follows,

9 (1). Positioning: Using PVC casing pipe the location was selected (Fig. 2a).

(2). Penetration of a casing pipe: PVC casing pipe was pushed into entire depth i.e. $600 \mathrm{~mm}$ using vibratory drop hammer.

12 (3). Excavation of sand: Using soil auger the sand inside casing pipe was removed.

13 (4). Pouring of sand: Pre-calculated amount of Solani sand was poured inside the casing pipe in three layers. Using a tamping rod, soil was compacted for each layer for achieving desired relative density (80\%).

15 (5). Removal of casing pipe: Casing pipe is slowly lifted, after completion of each compacted sand layer.

16 (6). Completion: Same procedure is repeated for all the four SCP system and shown in Fig. 2b.

17 The improvement in density of the prepared ground i.e. $40 \%$ density and $60 \%$ density with and without SCP installation was verified using cone penetrometer equipment. The penetration resistance values for every $100 \mathrm{~mm}$ depth were measured with and without SCP installation and the results are discussed in Section 4.1.

\section{$21 \quad 3.3$ Foundation model}

22 To study the effect of ground improvement-foundation interaction under repeated shaking events; scaled down 23 shallow footing model was used in this study. The footing was embedded at center inside the prepared ground and settlement response during repeated shaking conditions was assessed. For scaling, dynamic similitude laws proposed 25 by Moncarz and Krawinkler [1981] was adopted in present study and shown in Eq. 1.

$$
N_{(E I)}=N_{(K)} \times N_{(L)}^{3}
$$

$27 N_{(E I)}$ is the scale factor for flexural rigidity, $N_{(K)}$ is the stiffness scale factor, $N_{(L)}$ is the scale factor for linear dimensions. A scale factor $(\mathrm{N})$ of 10 was adopted and the foundation model with dimensions $115 \mathrm{~mm} \times 115 \mathrm{~mm} \times$ 
30mm was fabricated. The settlement of foundation model was measured after each shaking event. Similarly, for monitoring soil displacements, settlement plates were placed over the ground surface. After complete dissipation of generated pore water pressures from each shaking events; both foundation settlement and soil displacement for the treated and untreated soil deposit was measured and compared.

\subsection{Loading conditions}

In physical modelling studies, either reduced scale earthquake motion or sinusoidal wave motion was preferred to study the response of saturated ground deposits (Olarte et al. 2017; Ye et al. 2018; Wang et al. 2020). To simulate repeated shaking events, sinusoidal motions having incremental acceleration loading was selected and applied sequentially in this study. The occurrence of liquefaction and reliquefaction with and without treatment was assessed. The selection of repeated shaking was based on repeated foreshock and/or aftershock events associated with main-shock incidence observed during earthquake loading in the past. For experimental testing, sinusoidal acceleration loading having $0.1 \mathrm{~g}, 0.2 \mathrm{~g}, 0.3 \mathrm{~g}$, and $0.4 \mathrm{~g}$ intensity was selected and applied. The selected acceleration time history employed in this study is similar to Padmanabhan and Shanmugam (2020) simulating medium to high intensity of shaking. Further, frequency and shaking duration were kept constant as $5 \mathrm{~Hz}$ and 40s respectively, to examine the influence of longer shaking duration and frequency in influencing seismic response of soil

17 deposit(Yasuda et al. 2012).

18 The repeated incremental loading was applied to both SCP treated and untreated ground after complete dissipation 19 of excess pore water pressure (EPWP) generated during previous loading i.e. after application of $0.1 \mathrm{~g}$ acceleration 20 loading, the time taken for generation and dissipation of EPWP was monitored continuously through glass tube 21 piezometers. After complete dissipation of generated EPWP, subsequent acceleration loading of $0.2 \mathrm{~g}$ was applied.

22 The same was repeated for $0.3 \mathrm{~g}$ and then to $0.4 \mathrm{~g}$ acceleration loading. The variation in soil density, EPWP response,

23 foundation settlement and soil subsidence and cyclic stress ratio at repeated loading conditions were observed for each acceleration loading and the influence of these parameters were discussed in following sections.

\section{4. Experimental results and discussion}




\subsection{Effect of ground conditions on liquefaction and reliquefaction resistance for untreated and treated sand} deposits

In this section, the effect of in-situ ground density and its response under repeated loading conditions with and without treatment is discussed. The uniformity in ground preparation with depth for $40 \%$ and $60 \%$ ground is evaluated using a digital cone penetrometer. Similarly after installation of sand compaction piles and application of repeated acceleration loading; the variation in penetration resistance with depth was also assessed. From the obtained penetration resistance, the density of the ground was estimated. The penetration resistance at every $100 \mathrm{~mm}$ depth and corresponding relative density was estimated using Eq. 2 proposed by Jamiolkowski et al. (2003).

$$
D_{R}=100\left[0.268 \times \ln \left(\frac{q_{t} / \sigma_{a t m}}{\sqrt{\sigma_{v o}^{\prime} / \sigma_{a t m}}}\right)-0.675\right]
$$

$D_{R}$ is the relative density of the sample in percentage, $\sigma_{v o}^{\prime}$ is the effective overburden pressure $\left(\mathrm{kg} / \mathrm{cm}^{2}\right)$ and $q_{t}$ is the cone penetration resistance $\left(\mathrm{kg} / \mathrm{cm}^{3}\right)$. The variation in density before and after treatment and after application of sequential acceleration loading is discussed in the following sections.

\subsubsection{Variation in ground condition due to installation of SCPs}

The obtained cone penetration resistance and estimated density of the untreated and treated ground bed having $40 \%$ and $60 \%$ density is shown in Fig 3 (a) and (b) respectively. Inclusions of sand piles increased the penetration resistance of sands, and are higher at the bottom due to overburden effect, irrespective of initial density and improvement work. It is evident from the Figure 3 (b) that, wet sedimentation technique induced uniformity in sample preparation. The relative density of ground with depth after sample preparation is between $36 \%$ to $42 \%$ for $40 \%$ ground conditions and $57 \%$ to $62 \%$ for $60 \%$ ground conditions. The slight variation in relative density with depth as seen in Fig 3(b) may be due to the overburden effects induced by the top soil layers. However, the variation in density with depth both for $40 \%$ and $60 \%$ prepared ground found within 5\% suggesting that ground is uniform with depth. The effect of SCP installation on $40 \%$ and $60 \%$ density ground is also plotted on 3 (a) and (b) for better comparison. It can be seen that, density of the ground improved after installation of sand compaction pile system. For the SCP treated ground, the density increased between $46 \%$ to $53 \%$ and $65 \%$ to $70 \%$ for $40 \%$ and $60 \%$ relative density respectively. Overall, the percentage improvement with depth is in the range between $15 \%$ to $17 \%$ for both the ground conditions and found similar to real field situations (Hatanaka et al. 2008). As discussed, the installation of SCP system improved both density and rigidity of the saturated ground. This improves the seismic response of 
liquefiable deposit during dynamic loading conditions. However, the improvement in density induced by the SCP system during repeated shaking events and its influence on liquefaction and reliquefaction resistance is discussed in the following section.

\subsubsection{Effect of improvement in in-situ soil density due to Sand compaction pile system under repeated} loading

6 The effect of repeated acceleration loading on saturated ground deposit is discussed in this section. The application of repeated incremental acceleration loading is performed to the both unreinforced and reinforced ground only after complete dissipation of generated pore water pressure from previous loading. Also, penetration tests were carried out on both unreinforced and reinforced ground after each loading and corresponding penetration resistance and density was estimated. Fig. 4 (a) shows the obtained penetration resistance, under repeated loading for both treated and untreated ground prepared with $40 \%$ and $60 \%$ density. The continuous application of acceleration loading induces reorientation of sand particles and causing soil densification after each loading. However, the continuous change in soil fabric and uneven soil deposition resulted in non-uniform densification with depth. This was evident from both penetration resistance and relative density results shown in Fig 4 and 5 for untreated and treated deposits. In case of treated ground, combined of installation effects of sand compaction pile system induces uniformity in density with depth. Further, the continuous occurrence of soil densification due to repeated loading resulted in

17 higher penetration resistance than untreated ground. The continuous increment in density of the surrounding ground due to continuous shaking imparts effective confinement to the reinforcing column which further improves the seismic resistance of the ground. Overall, the initial improvement in density due to SCP installation i.e. $28 \%$ for $40 \%$ ground and $18 \%$ for $60 \%$ ground contributed in mitigating liquefaction at $0.1 \mathrm{~g}$ acceleration loading. The effect of soil densification induced by SCP system and unreinforced ground was further validated in terms of pore pressure response and discussed in the following section. Densification mechanism induced by SCP system was critical in controlling the generation of EPWP. Compared to untreated sand deposits, improvement percentage in soil density was reported as $17 \%$ and $15 \%$ after the installation of SCP's, and $15 \%$ and $13 \%$ improved was observed at the end of final shaking event for $40 \%$ and $60 \%$ dense ground conditions respectively. Selection of improvement ratio and pattern of installation are critical in the improvement of sand density reinforced with sand compaction piles.

27 Reorientation of soil particles and soil consolidation are mainly responsible for improvement in sand density under the application of repeated shaking events. 
3 Significance of void ratio in liquefaction potential is another influencing parameter to assess the efficacy of any

4 ground improvement technique. As discussed, the reorientation of sand particles and change in soil fabric structure

5 due to repeated shaking events resulted in redistribution of void ratio for untreated and treated ground. The void 6 ratio variation with depth was estimated using equation 3.

$$
e=e_{\max }-D_{R}\left(e_{\max }-e_{\min }\right)
$$

8 Where, $e$ and $D_{R}$ are void ratio and relative density of the sand at that particular depth and $e_{\max }$ and $e_{\min }$ are the 9 maximum and minimum void ratio as shown in Table 1. The variation in void ratio with depth for repeated 10 acceleration loading is shown in Fig. 6 . The reduction in void ratio was about $1.5 \%$ to $6 \%$ and $1.2 \%$ to $4.5 \%$ in case 11 of treated ground compared to untreated for $40 \%$ and $60 \%$ density. The reduction in void ratio validated the occurrence of improvement in density due to acceleration loading. The reduction percentage was found higher for

$1340 \%$ ground than $60 \%$ ground as expected. Further, the reduction in void ratio due to density improvement induced 14 by the SCP system additionally highlights the beneficial effect of reinforcement system in mitigating generation of 15 pore water pressures especially during repeated shaking events.

\section{$17 \quad 4.2$ Influence of pore water pressure response on reliquefaction resistance}

18 Generally, the occurrence of liquefaction and reliquefaction in saturated sand deposits was assessed through generated pore water pressure and estimated pore pressure ratio. In this study, two glass tube piezometers were used for monitoring pore pressure response at $0.2 \mathrm{~m}$ and $0.4 \mathrm{~m}$ depth within the prepared ground. Fig. 7 and 8 shows the

21 obtained time history of excess pore water pressure (EPWP) at different depths for $40 \%$ and $60 \%$ density ground 22 with and without SCP system at repeated incremental acceleration loading conditions i.e. $0.1 \mathrm{~g}, 0.2 \mathrm{~g}, 0.3 \mathrm{~g}$ and $0.4 \mathrm{~g}$ at

$235 \mathrm{~Hz}$ frequency with 40 seconds shaking duration. During experimental testing, application of sequential 24 acceleration loading to the ground was carried only after dissipation of generated pore water pressure from previous 25 loading which can be estimated from the installed glass piezometers inside the ground.

26 In case of untreated ground, generation of EPWP was observed maximum for $40 \%$ density ground than $60 \%$ density 27 as expected. However, due to repeated acceleration loading conditions; increment in density with depth was observed for both the ground conditions. The increment in density was evaluated using cone penetrometer 
equipment. Further with the increase in the density of the ground i.e. $60 \%$, the increment in density with depth under repeated shaking also increases. In case of untreated ground conditions, the increment in density under repeated shaking conditions was 58 to $68 \%$ for $40 \%$ ground and 18 to $30 \%$ for $60 \%$ ground respectively and found linearly increases with depth. The generation of pore water pressures under repeated shaking events suggesting that, improvement in density was not uniform with depth resulting in generation of pore water pressures from bottom to top and made soil at shallow depth more susceptible to liquefaction and reliquefaction. This was found evident from the time of liquefaction occurrence under repeated shaking events. The liquefaction time can be assessed in terms of build-up time $\left(t_{1}\right)$, duration $\left(t_{2}\right)$ and dissipation of excess pore water pressures $\left(t_{3}\right)$. The obtained results were tabulated in Table2. In case of untreated saturated ground, $\left(t_{1}\right)$ decreases with the increase in applied acceleration loading. Though density plays a major role improving seismic response of saturated ground, occurrence of nonuniformity in density induces generation of pore water pressures and make soil more susceptible to reliquefaction in case of repeated shaking events.

When SCP treated ground subjected to repeated shaking events, generation of pore water pressures were found minimum compared to untreated ground. The same can be verified from Fig 7 and 8 respectively. During lower to medium acceleration loading conditions (i.e. $0.1 \mathrm{~g}$ and $0.2 \mathrm{~g}$ ) generation of pore water pressures was not observed at $0.1 \mathrm{~g}$ loading and limited pore pressure was generated at $0.2 \mathrm{~g}$ shaking for both $40 \%$ and $60 \%$ ground conditions. The initial improvement in density due to SCP installation improves seismic resistance during low to medium acceleration loading. This can be verified the obtained improvement in density values obtained after SCP installation and density results after repeated loading events. Interestingly, in all the cases SCP treated ground showed uniformity in density with depth which improves the seismic resistance of saturated ground during dynamic loading. Occurrence of uniformity in ground conditions during initial loading mitigates generation of pore water pressures and during repeated acceleration loading, limited generation of pore water pressures were observed. The reduction in generated excess pore water pressure during repeated loading was found to be 16 to $40 \%$ at $0.4 \mathrm{~m}$ depth and 20 to $46 \%$ at $0.2 \mathrm{~m}$ depth for $40 \%$ relative density and 17 to $25 \%$ at $0.4 \mathrm{~m}$ depth and 18 to $25 \%$ at $0.2 \mathrm{~m}$ depth for $60 \%$ density ground. Further, the time of liquefaction increases for the SCP treated ground which verified the performance of the improvement system under repeated shaking events. Further, the reduction in generated pore water pressures at $40 \%$ ground condition (i.e. $40 \%$ to $46 \%$ for $0.4 \mathrm{~m}$ and $0.2 \mathrm{~m}$ depth respectively at the end of repeated loading) suggesting that, installation of SCP inside the ground limits occurrence of liquefaction and 
reliquefaction and stabilise the soil at shallow depth. The uniformity in soil densification due to SCP installation

2 additionally improves the seismic resistance of the saturated ground deposit. Also, the continuous generation of pore

3 water pressures during high to intense acceleration loading suggested the influence of area replacement ratio in

4 improving the seismic performance of saturated ground deposits. The improvement ratio selected for the study i.e.

$53 \%$ performs better during low to medium repeated acceleration loading conditions. However, during very high to

6 intense loading; the selected area replacement ratio was not found adequate and suggested the need of proper area

7 replacement ratio for further improving the seismic resistance of the ground.

8 The effect of pore pressure ratio estimated from the generated pore water pressure for treated and untreated ground

9 is discussed in this section. It can be calculated using the formula

$$
r_{u}=\frac{U}{\sigma_{v o}^{\prime}}
$$

11 Where $U$ is the excess pore water pressure (in $k P a$ ) and $\sigma_{v o}^{\prime}$ is the effective overburden pressure of the sand deposits

12 calculated at that particular depth (in $k P a$ ).

13 The estimated pressure ratio for the treated and untreated ground for varying density under repeated shaking events

14 is shown in Fig. 9 and 10. It was observed that, the estimated pore pressure ratio for the treated and untreated ground

15 found to be increases with the increase in acceleration loading under repeated shaking events. The generation

16 of $\left(r_{u}\right)$ is found higher at shallow depth i.e. $0.2 \mathrm{~m}(\mathrm{~T})$ than at bottom $0.4 \mathrm{~m}$ depth (B) due to soil densification and

17 overburden effects. Comparatively, the estimated pore pressure ratio for the treated deposits found lower than

18 untreated ground. This was more pronounced in case of $40 \%$ ground. The observed reduction in maximum $\left(r_{u}\right)$ was

19 found to be 15 to $34 \%$ at Top (T) and 23 to $40 \%$ at Bottom (B) depth for $40 \%$ density and 26 to $36 \%$ and 26.5 to

$2036.5 \%$ at Top (T) and Bottom (B) depth respectively for $60 \%$ density ground. This verified the efficiency of SCP

21 system in inducing soil densification mechanism in which contributed in mitigating generation of EPWP under

22 repeated shaking events especially at loose ground conditions. Further, due to uniformity in ground density due to

23 SCP installation induce uniform improvement in ground density during repeated shaking which further contribute in

24 minimizing generation of pore water pressures. Due to this uniformity in densification, no liquefaction and

25 reliquefaction was observed on the treated ground. In case of untreated ground, occurrence of non-uniformity in

26 density with depth induces upward generation of pore water pressures from bottom to top and made soil at shallow

27 depth more vulnerable to liquefaction and reliquefaction. The selected area replacement ratio for the SCP system 
mitigates generation of pore water pressure at $0.1 \mathrm{~g}$ loading and minimizes generation of pore water pressure during repeated shaking events. This improves the seismic response of the ground against liquefaction and reliquefaction.

\subsection{Foundation settlement and soil subsidence}

5

Occurrence of liquefaction and reliquefaction induce both foundation and soil located at shallow depth more susceptible to failures. Hence, in this study, the stability of shallow foundation resting on saturated ground under repeated dynamic loading was investigated. Using scaled foundation model, the observed foundation settlement and soil displacement was measured and compared. Using LVDT and settlement plates, both foundation settlement and soil displacement for the treated and untreated ground was measured and compared.

The obtained foundation settlement corresponding to $40 \%$ and $60 \%$ relative density subjected to repeated acceleration loading for both the treated and untreated ground is shown in Fig. 11. In both cases, the footing model was placed at the center of the prepared ground. The initial improvement induced by SCP system on $40 \%$ and $60 \%$ ground enhances the stability of the foundation and no foundation settlement was observed after $0.1 \mathrm{~g}$ acceleration loading. As discussed in the previous section, improvement in density mitigates generation of pore water pressure thereby improving the seismic response of the ground at $0.1 \mathrm{~g}$ acceleration loading. However, under repeated shaking events and with the limited generation of pore water pressures, settlement of the footing was observed from $0.2 \mathrm{~g}$ to $0.4 \mathrm{~g}$ acceleration loading. The generation of pore water pressured mainly due to the application of longer duration of shaking which induces generation of pore water pressure from bottom to top. In case of treated ground, the uniformity in density with depth delays generation of pore water pressure and in case of untreated deposits, the nonuniformity with depth due to repeated shaking induces rapid generation of pore water pressures from bottom to top. This made soil at shallow depth more vulnerable and induces increment in foundation settlement. The reduction in foundation settlement for the treated ground found to be $25 \%, 19 \%$ and $17 \%$ for $40 \%$ and $17 \%, 16 \%$ and $15 \%$ for $60 \%$ density ground at $0.2 \mathrm{~g}, 0.3 \mathrm{~g}$ and $0.4 \mathrm{~g}$ respectively.

The performance of SCP system was further validated by comparing estimated pore water pressure ratio $\left(r_{u}\right)$ and obtained foundation settlement under repeated shaking events. The estimated $\left(r_{u}\right)$ based on the generated EPWP and corresponding foundation settlement was shown in Fig. 12.With the reduction in maximum $\left(r_{u}\right)$ for untreated and treated ground i.e. 15 to $34 \%$ for $40 \%$ ground and 26 to $36 \%$ for $60 \%$ density ground at shallow depths $(0.2 \mathrm{~m})$, the reduction in foundation settlement was about 17 to $25 \%$ and 15 to $17 \%$ respectively. The reduction in maximum 
$\left(r_{u}\right)$ at shallow depths verified the efficacy of treated sand deposits in mitigating generation of EPWP, foundation settlement reduction and improvement in seismic resistance of prepared ground against liquefaction and reliquefaction. Thus, the soil densification mechanism induced by SCP system with 3\% area replacement ratio found successful in mitigating reliquefaction phenomenon even during high intense shaking events $(0.4 \mathrm{~g})$ and with longer shaking duration (40s).

6 The effect of selected ground improvement system was also assessed by estimating soil displacement using 7 settlement plates. The measured soil subsidence under successive shaking events is shown in Fig. 13. Similar to 8 foundation settlement, no soil displacement was observed at $0.1 \mathrm{~g}$ loading in treated ground. Also, the observed soil 9 displacement increases for the treated ground which mainly due to densification effects of SCP system. The increase 10 in soil displacement was about 15 to $40 \%$ for $40 \%$ dense ground and 27 to $50 \%$ for $60 \%$ dense ground respectively.

11 The increment in soil displacement verified the occurrence of soil densification. From the density values, the 12 improvement was further verified and found uniform with depth. Thus, SCP treated ground improves the seismic 13 performance of the ground, minimizes foundation settlement and improves the stability of the ground even under 14 repeated acceleration loading conditions.

\subsection{Effect of CSR under repeated shaking events}

17 Liquefaction potential and seismic demand of saturated sand deposits are generally evaluated in terms of Cyclic 18 Stress Ratio (CSR) (Youd et al. 2001).To quantify the influence of densification mechanism induced by sand 19 compaction pile improvement system; an attempt has been made to evaluate CSR for the treated and untreated sand 20 deposits subjected to repeated incremental shaking events. CSR was estimated using equation (5) proposed by Seed and Idriss (1971),

$$
\operatorname{CSR}=\left(\frac{\tau_{a v}}{\sigma_{v o}^{\prime}}\right)=0.65 \times\left(\frac{a_{\max }}{g}\right)\left(\frac{\sigma_{v o}}{\sigma_{v o}^{\prime}}\right) r_{d}
$$
the total and effective vertical overburden stress and $r_{d}$ is stress reduction coefficient which decreases along the depth and calculated using Liao and Whitman (1986) recommendations as shown in Eq. 6

$$
r_{d}=1.0-0.00765 z \text { For } z \leq 9.15 m
$$

$27 \quad z$ is the depth of ground surface in $\mathrm{m}$. 
1 The estimated CSR values were compared with maximum pore water pressure ratio for treated and untreated sand

2 deposits to verify the performance of SCP system. The obtained result is shown in Fig. 14 for $40 \%$ and 60\% ground.

3 Installation of SCP system delays generation of EPWP resulting in reduction in pore pressure ratio for both the

4 ground conditions. Also, CSR found lesser due to improvement in density on the treated ground. This is also verified

5 through Fig. 15. Interestingly, the reduction in CSR and pore pressure ratio was found more at shallow depths i.e.

$60.2 \mathrm{~m}$ depth. The maximum reduction was about $12 \%$ for $40 \%$ ground and $8 \%$ for $60 \%$ density ground for $3 \%$ area

7 replacement ratio of SCP system. This verified the performance of SCP improvement system against occurrence of

8 liquefaction and reliquefaction when subjected to repeated shaking events. The reduction in CSR at $0.4 \mathrm{~m}$ depth was

9 about 2 to $6 \%$ and 2 to $5 \%$ for $40 \%$ and $60 \%$ density and not much significant due to overburden effects. The

10 estimated CSR values, verified the need of selecting adequate area replacement system in improving the density of

11 the ground. This will helpful in mitigating generation of pore water pressures even at repeated shaking events. In

12 this study, the SCP improvement system found effective in mitigating generation of pore water pressures, minimizes

13 foundation settlement and improves seismic response of sand deposit especially at shallow depth. However, the

14 generated pore water pressures under repeated loading highlighting the selection of proper area replacement ratio for 15 improved performance.

16

\section{5. Conclusions}

18 The present study assessed the performance of SCP system in improving liquefaction and reliquefaction resistance 19 of $40 \%$ and $60 \%$ saturated sand deposits under repeated incremental acceleration loading conditions. The 20 investigations were carried using 1 -g shaking table at $0.1 \mathrm{~g}, 0.2 \mathrm{~g}, 0.3 \mathrm{~g}$, and $0.4 \mathrm{~g}$ sinusoidal acceleration loading 21 conditions with $5 \mathrm{~Hz}$ frequency having 40s shaking duration. For ground improvement four sand compaction piles 22 installed in square pattern with the spacing of $450 \mathrm{~mm}$ through vibratory action with an improvement ratio $3 \%$ was

23 chosen and installed. The performance of the ground with and without SCP system works was compared in terms of 24 soil densification effects, generated pore water pressure and estimated pore pressure ratio, soil displacement and 25 foundation settlement. Based on the obtained and estimated results, beneficial effects of SCP improvement system in 26 mitigating liquefaction and reliquefaction were evaluated. The following conclusions were drawn from the 27 experimental results and observations: 


\section{Acknowledgments} shaking events.

1

1) Installation of sand compaction pile group uniformly increases the relative density of saturated sand deposits. The improvement in soil densification due to SCP installation resists generation of pore water pressures and mitigates liquefaction during low to medium acceleration loading. The soil densification effects due to repeated loading further benefitted reduction in pore pressure generation about $41 \%, 18 \%, 14 \%$ in case of $40 \%$ dense ground and $21 \%, 17 \%$ and $15 \%$ for $60 \%$ ground conditions at $0.2 \mathrm{~g}, 0.3 \mathrm{~g}$ and $0.4 \mathrm{~g}$ acceleration loading at $0.2 \mathrm{~m}$ depth respectively. Thus the reduction in pore pressure generation indicates the improvement in soil resistance against liquefaction and reliquefaction at shallow depth.

2) In case of untreated ground, application of repeated incremental shaking events also induces soil densification effects. However, the redistributed soil grains after each loading were not uniform with depth causing continuous generation of pore water pressure despite of improvement in density. Thus, the generated pore water pressures from bottom to top made soil at shallow depth more susceptible to reliquefaction during subsequent

3) The soil densification effect induced by SCP system improves the stability of foundation located at shallow depth even during repeated shaking events. Compared to untreated ground, SCP improved ground shows reduction in foundation settlement of about $17 \%$ to $25 \%$ for $40 \%$ ground and $15 \%$ to $17 \%$ for $60 \%$ ground under $0.2 \mathrm{~g}$ to $0.4 \mathrm{~g}$ repeated loading events with $3 \%$ improvement ratio of SCP system. Also, no foundation settlement was observed at $0.1 \mathrm{~g}$ acceleration loading for both $40 \%$ and $60 \%$ ground conditions due to density improvement effects. Thus, the SCP improvement system can be a viable improvement technique for improving seismic performance of saturated sand deposits even during repeated loading events. As discussed, the stability of foundation can be further improved by selecting proper area replacement ratio of SCP system. 
1 The authors would like to thank the Director, CSIR-Central Building Research Institute, Roorkee, for giving

2 permission to publish this research work. The authors would also like to thank the Head, Geotechnical Engineering

3 Division, CSIR-CBRI for his continuous support during this research work.

4

5

6

7

8

9

10

11

12

13

14

15

16

17

18

19

20

21

22

23

24

25

26

27

28

References 
1. ASTM D 3441 - 16(1984) The Static Cone Penetrometer, The Equipment and using the Data

2. Bahmanpour A, Towhata I, Sakr M, Mahmoud M, Yamamoto Y, Yamada S (2019)The effect of underground columns on the mitigation of liquefaction in shaking table model experiments. Soil Dynamics and Earthquake Engineering116 pp.15-30

3. Bureau of Indian Standards IS 1893 (2016)Criterion for Earthquake Resistant Design of Structures, General Provisions and Buildings,Part I

4. Bureau of Indian Standards IS 2720(1985)Methods of Test for Soils - Grain Size Analysis, Part IV

5. Bureau of Indian Standards IS 2720(2006)Methods of Test for Soils-Determination of Density Index for Cohesionless Soils, Part XIV

6. Bureau of Indian Standards IS 4968(1976)Method for Subsurface Sounding of Soils - Static Cone Penetration Test, Part III

7. Darby KM, Boulanger RW, DeJong JT, Bronner JD (2018): Progressive changes in liquefaction and cone penetration resistance across multiple shaking events in centrifuge tests. Journal of Geotechnical and Geoenvironmental Engineering 145(3) p.04018112

8. Dobry R, Abdoun T, Stokoe KH, Moss RES, Hatton M, El Ganainy H(2015) Liquefaction potential of recent fills versus natural sands located in high-seismicity regions using shear-wave velocity, Journal of Geotechnical and Geoenvironmental Engineering 141(3) p.04014112

9. El-Sekelly W, DobryR, Abdoun T, Steidl JH (2016)Centrifuge modelling of the effect of preshaking on the liquefaction resistance of silty sand deposits. Journal of Geotechnical and Geoenvironmental Engineering 142(6) p.04016012

10. Fallahzadeh M, Haddad A, Jafarian Y, Lee CJ (2019) Seismic performance of end-bearing piled raft with countermeasure strategy against liquefaction using centrifuge model tests. Bulletin of Earthquake Engineering, 17(11), 5929-5961.

11. Ha IS, Olson SM, Seo MW, Kim MM (2011)Evaluation of reliquefaction resistance using shaking table tests. Soil Dynamics and Earthquake Engineering31(4),682-691

12. Hamayoon K, Morikawa Y, Oka R, Zhang F (2016)3D dynamic finite element analyses and $1 \mathrm{~g}$ shaking table tests on seismic performance of existing group-pile foundation in partially improved grounds under dry condition. Soil Dynamics and Earthquake Engineering90, 196-210

13. Harada K, Ohbayashi J (2017) Development and improvement effectiveness of sand compaction pile method as a countermeasure against liquefaction. Soil and Foundations 57(6),980-987

14. Hatanaka M, Feng L, Matsumura N, Yasu H(2008) A study on the engineering properties of sand improved by the sand compaction pile method.Soils and Foundations 48(1), 73-85

15. Hossain MZ, Abedin MZ, Rahman MR, Haque MN, Jadid R (2020) Effectiveness of sand compaction piles in improving loose cohesionless soil. Transportation Geotechnics 26, p. 100451

16. Jamiolkowski M, Lo Presti DCF, Manassero M (2003):Evaluation of relative density and shear strength of sands from CPT and DMT. In Soil behavior and soft ground construction,201-238

17. Kitazume M (2005) The sand compaction pile method. CRC Press 
18. Liao SS, Whitman RV (1986)Overburden correction factors for SPT in sand, Journal of Geotechnical Engineering.112(3), 373-377

19. Moncarz PD, Krawinkler H (1981)Theory and application of experimental model analysis in earthquake engineering. Vol. 50, California: Stanford University

20. Mulilis JP, Arulanandan K, Mitchell JK, Chan CK, Seed HB (1977)Effects of sample preparation on sand liquefaction. Journal of the Geotechnical Engineering Division,03(2),91-108

21. Oda M, Kawamoto K, Suzuki K, Fujimori H, Sato M (2001)Microstructural interpretation on reliquefaction of saturated granular soils under cyclic loading. Journal of Geotechnical and Geoenvironmental Engineering, 127(5), 416-423

22. Okamura M, Ishihara M, Oshita T(2003) Liquefaction resistance of sand improved with sand compaction piles.Soils and Foundations,435, 175-187

23. Okamura M, Ishihara M, Tamura K (2006)Degree of saturation and liquefaction resistances of sand improved with sand compaction pile.Journal of Geotechnical and Geoenvironmental Engineering 132,258264

24. Olarte J, Paramasivam B, Dashti S, Liel A, Zannin J (2017)Centrifuge modelling of mitigation-soilfoundation-structure interaction on liquefiable ground. Soil Dynamics and Earthquake Engineering,97, 304323

25. Padmanabhan G, Shanmugam GK (2020)Reliquefaction Assessment Studies on Saturated Sand Deposits under Repeated Acceleration Loading Using 1-g Shaking Table Experiments. Journal of Earthquake Engineering, 1-23

26. Seed HB, Idriss IM (1971)Simplified procedure for evaluating soil liquefaction potential. Journal of Soil Mechanics Foundations Division

27. Tatsuoka F, Sakamoto M, Kawamura T, Fukushima S (1986)Strength and deformation characteristics of sand in plane strain compression at extremely low pressures.Soils and Foundations, 26(1), 65-84

28. Tokimatsu K, Yoshimi Y, Ariizumi K (1990) Evaluation of liquefaction resistance of sand improved by deep vibratory compaction.Soils and Foundations, 30(3), 153-158

29. Tsuchida H (1970) Prediction and countermeasure against the liquefaction in sand deposits. In Abstract of the seminar in the Port and Harbour Research Institute,31-33

30. Wang J, Salam S, Xiao M (2020)Evaluation of the effects of shaking history on liquefaction and cone penetration resistance using shake table tests.Soil Dynamics and Earthquake Engineering,131, p.106025

31. Xenaki VC, Athanasopoulos GA (2003)Liquefaction resistance of sand-silt mixtures: an experimental investigation of the effect of fines. Soil Dynamics and Earthquake Engineering,23(3), 1-12

32. Yamada S, Takamori T, and Sato K (2010)Effects on reliquefaction resistance produced by changes in anisotropy during liquefaction. Soils and Foundations,50(1), 9-25

33. Yasuda S, Harada K, Ishikawa K, Kanemaru Y (2012)Characteristics of liquefaction in Tokyo Bay area by the 2011 Great East Japan earthquake. Soils and Foundations,52(5), 793-810 
12

13

14

15

16

17

18

19

20

21

22

23

24

25

26

27

28

29

30

31

32

33

34

35

36

37

.

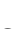

34. Ye B, Ye G, Zhang F, Yashima A (2007)Experiment and numerical simulation of repeated liquefactionconsolidation of sand. Soils and Foundations,47(3), 547-558

35. Ye B, Hu H, Bao X, LuP (2018)Reliquefaction behaviour of sand and its mesoscopic mechanism. Soil Dynamics and Earthquake Engineering,114, 12-21

36. Youd TL, Idriss IM, Andrus RD, Arango I, Castro G, Christian JT, Dobry R, Finn WDL, Harder Jr LF, Hynes ME, Ishihara K, Koester JP, Liao SSC, Marcuson III WF, Martin GR, Mitchell JK, Moriwaki Y, Power MS, Robertson PK, Seed RB, Stokoe II KH (2001)Liquefaction resistance of soils: summary report from the 1996 NCEER and 1998 NCEER/NSF workshops on evaluation of liquefaction resistance of soils.Journal of Geotechnical and Geoenvironmental Engineering, 817-833

.

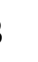

4

6

18

9

0

2

4

5

7

9

19

7


List of figures

Figure $1 \quad$ Grain size distribution curve of sand used for tests

Figure 2 Installation of SCP group in stages (a) Mark the predetermined positions of improvement system, (b) Completed SCP system, (c) Foundation model embedded in treated ground.

Figure 3 Initial prepared ground conditions for SCP treated and untreated (UT) soil (a) Cone penetration resistance; (b) Relative density (RD).

Figure 4 Cone penetration resistance variations for SCP treated and untreated (UT) soil conditions (a) $40 \%$ relative density; (b) $60 \%$ relative density.

Figure 5 Relative density variations for SCP treated and untreated (UT) soil conditions (a) $40 \%$ relative density; (b) $60 \%$ relative density.

Figure 6 Void ratio variations with respect to depth for SCP treated and untreated (UT) soil conditions (a) $40 \%$ relative density; (b) $60 \%$ relative density.

Figure 7 Time history of EPWP for treated and untreated soil conditions at top piezometer (a) $0.1 \mathrm{~g}$; (b) 0.2 g; (c) $0.3 \mathrm{~g}$; (d) $0.4 \mathrm{~g}$.

Figure 8 Time history of EPWP for treated and untreated soil conditions at bottom piezometer (a) $0.1 \mathrm{~g}$; (b) $0.2 \mathrm{~g}$; (c) $0.3 \mathrm{~g}$; (d) $0.4 \mathrm{~g}$.

Figure 9 Time history of Pore water pressure ratio for SCP treated and untreated soil conditions for $40 \%$ relative density (a) $0.1 \mathrm{~g}$; (b) $0.2 \mathrm{~g}$; (c) $0.3 \mathrm{~g}$; (d) $0.4 \mathrm{~g}$.

Figure 10 Time history of Pore water pressure ratio for SCP treated and untreated soil conditions for $60 \%$ relative density (a) $0.1 \mathrm{~g}$; (b) $0.2 \mathrm{~g}$; (c) $0.3 \mathrm{~g}$; (d) $0.4 \mathrm{~g}$.

Figure 11 Foundation settlement at varying accelerations for $40 \%$ and $60 \%$ relative density (RD) for treated and untreated soil conditions.

Figure 12 Untreated and treated foundation settlement versus maximum pore water pressure ratio (a) $40 \%$ relative density; (b) $60 \%$ relative density.

Figure 13 Surface soil displacement at varying accelerations for $40 \%$ and $60 \%$ relative density (RD) for treated and untreated soil conditions.

Figure 14 Untreated and treated cyclic stress ratio versus maximum pore water pressure ratio (a) $40 \%$ relative density; (b) $60 \%$ relative density. 
Figure 15 Untreated and treated cyclic stress ratio versus time taken to attain maximum EPWP (a) $40 \%$ relative density; (b) $60 \%$ relative density.

1

2

3

4

5

6

7

8

9

10

11

12

13

14

15

16

17

18

19

20

21

22

23

24

25

26 
$1 \quad$ List of tables

Table $1 \quad$ Index properties of the test sand

Table 2 Effect of SCP on $t_{1}, t_{2}$, and $t_{3}$ 


\section{Figures}

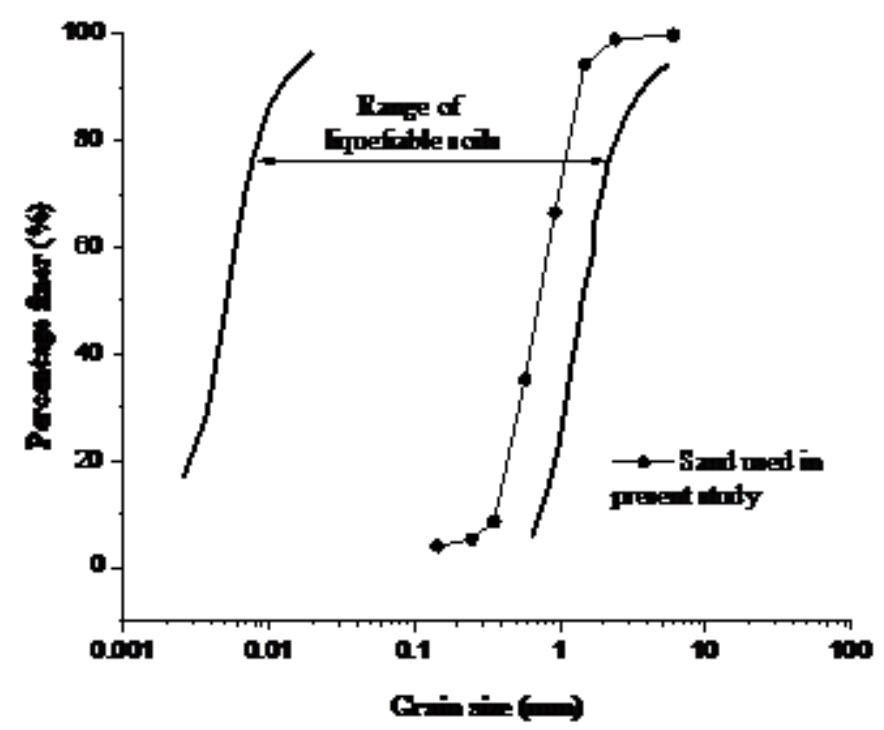

Figure 1

Grain size distribution curve of sand used for tests

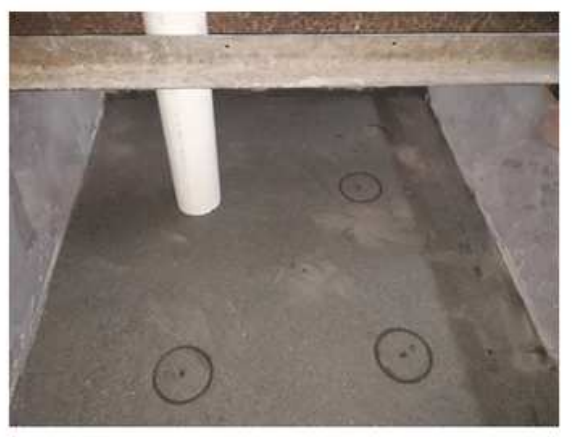

(a)

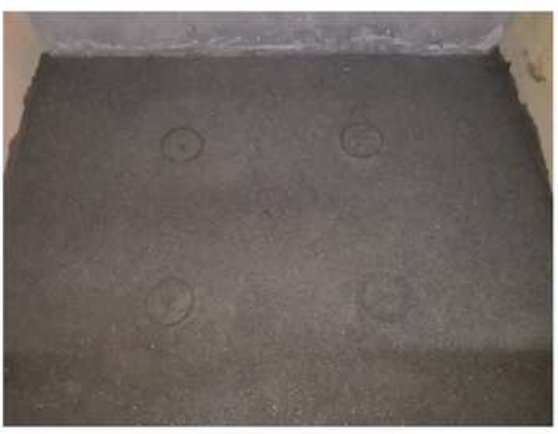

(b)

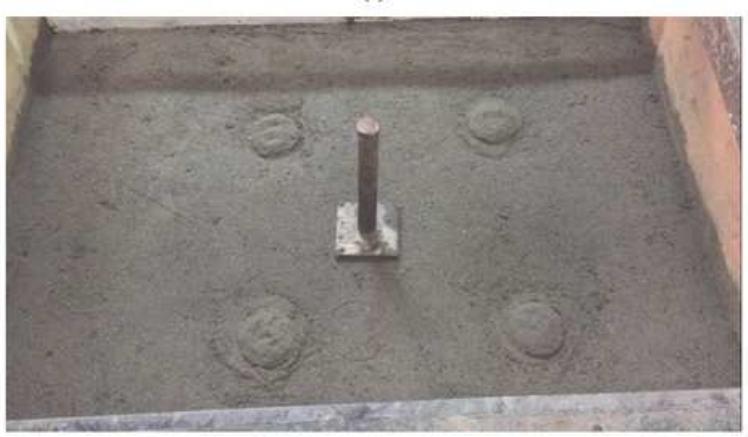

(c)

Figure 2

Installation of SCP group in stages (a) Mark the predetermined positions of improvement system, (b) Completed SCP system, (c) Foundation model embedded in treated ground. 


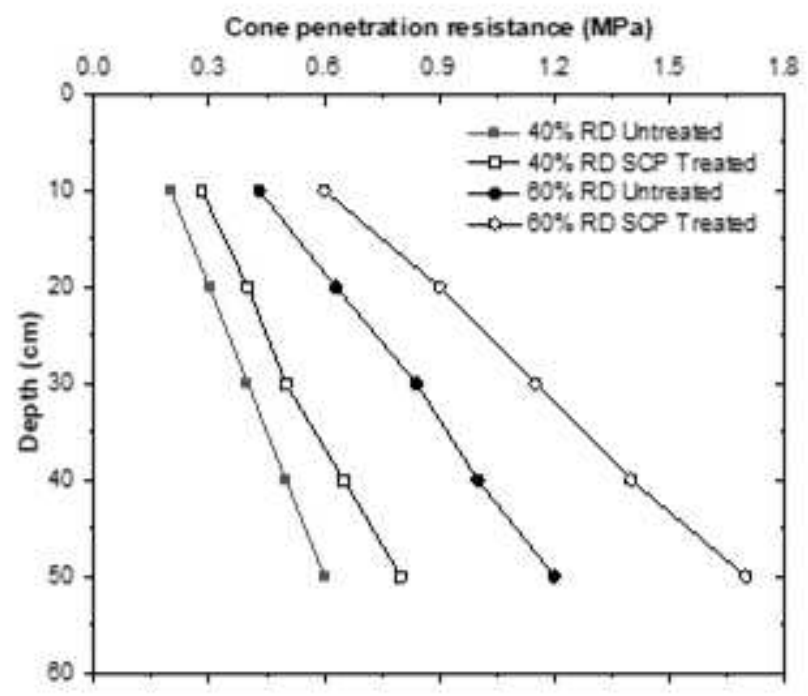

(a)

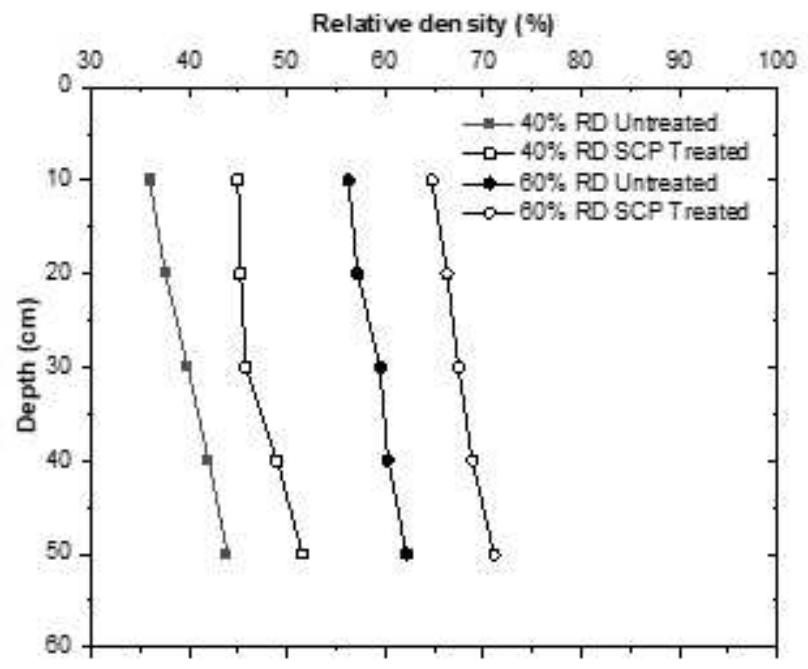

(b)

\section{Figure 3}

Initial prepared ground conditions for SCP treated and untreated (UT) soil (a) Cone penetration resistance; (b) Relative density (RD). 


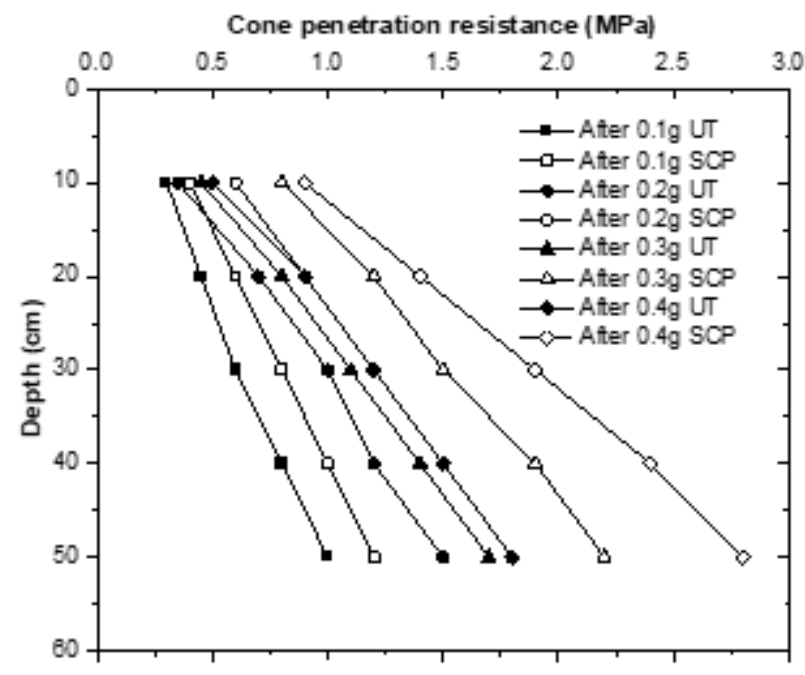

(a)

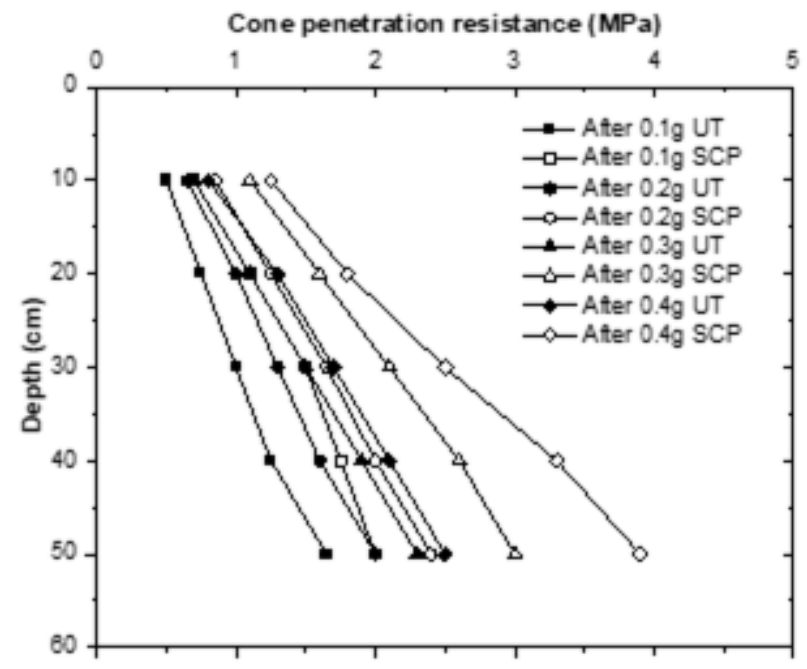

(b)

\section{Figure 4}

Cone penetration resistance variations for SCP treated and untreated (UT) soil conditions (a) $40 \%$ relative density; (b) $60 \%$ relative density. 


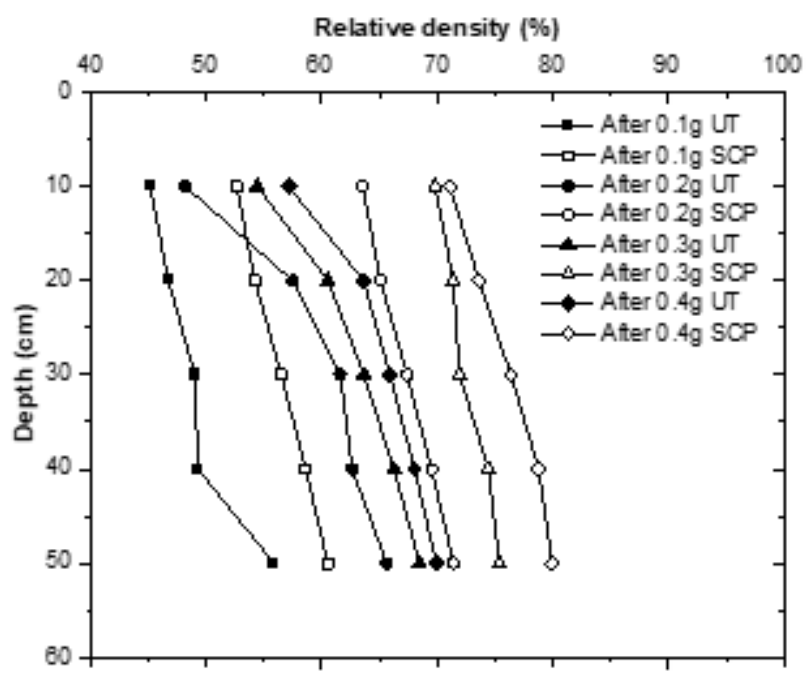

(a)

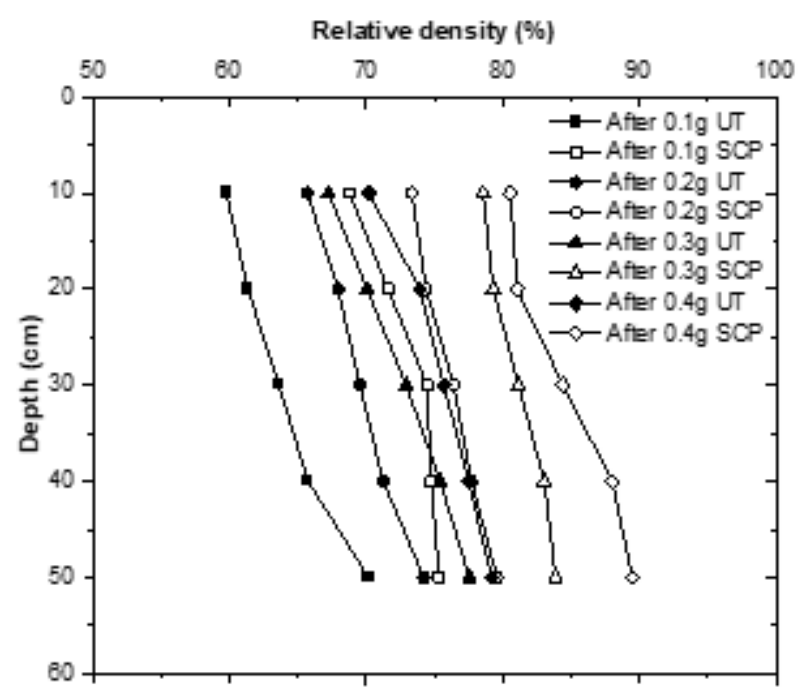

(b)

Figure 5

Relative density variations for SCP treated and untreated (UT) soil conditions (a) 40\% relative density; (b) $60 \%$ relative density. 


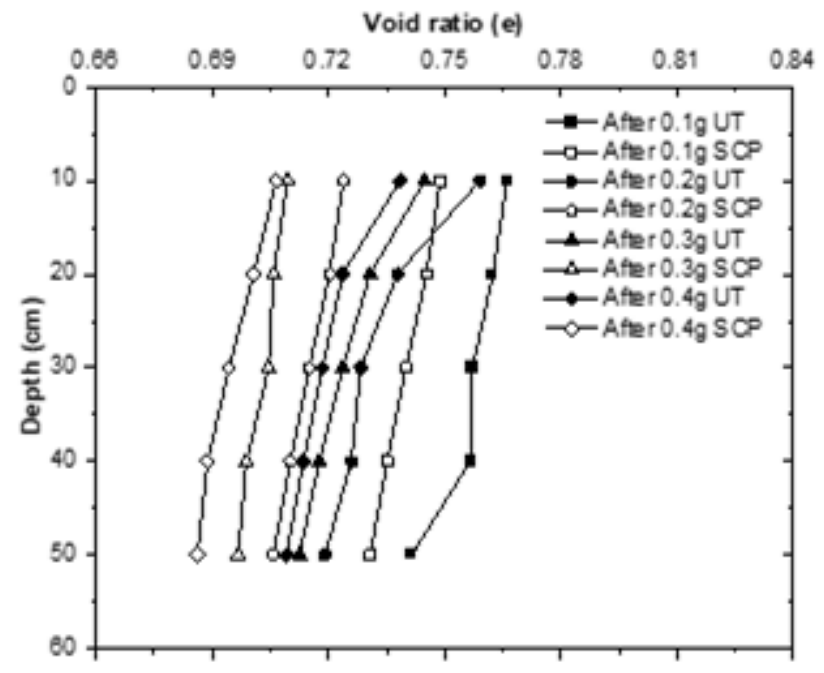

(a)

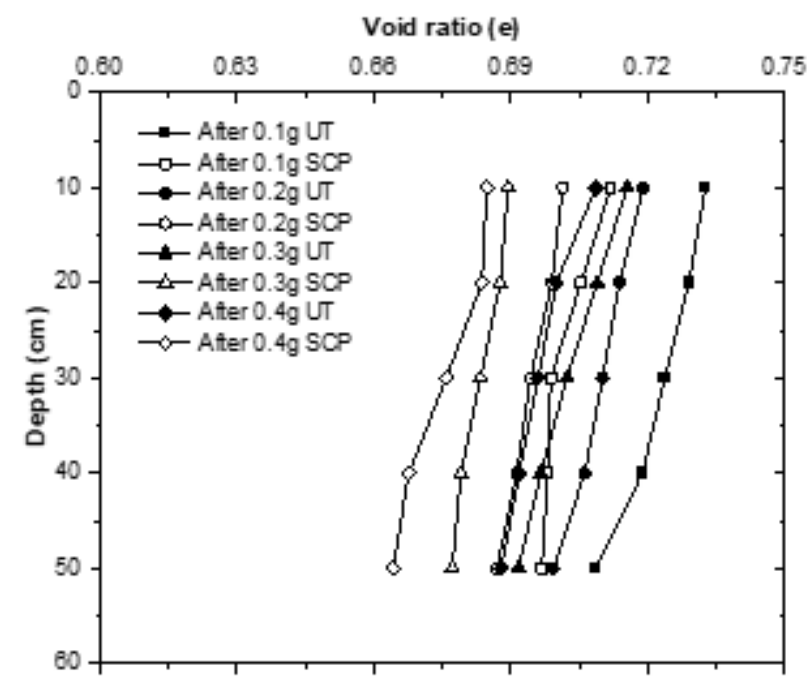

(b)

Figure 6

Void ratio variations with respect to depth for SCP treated and untreated (UT) soil conditions (a) $40 \%$ relative density; (b) $60 \%$ relative density. 


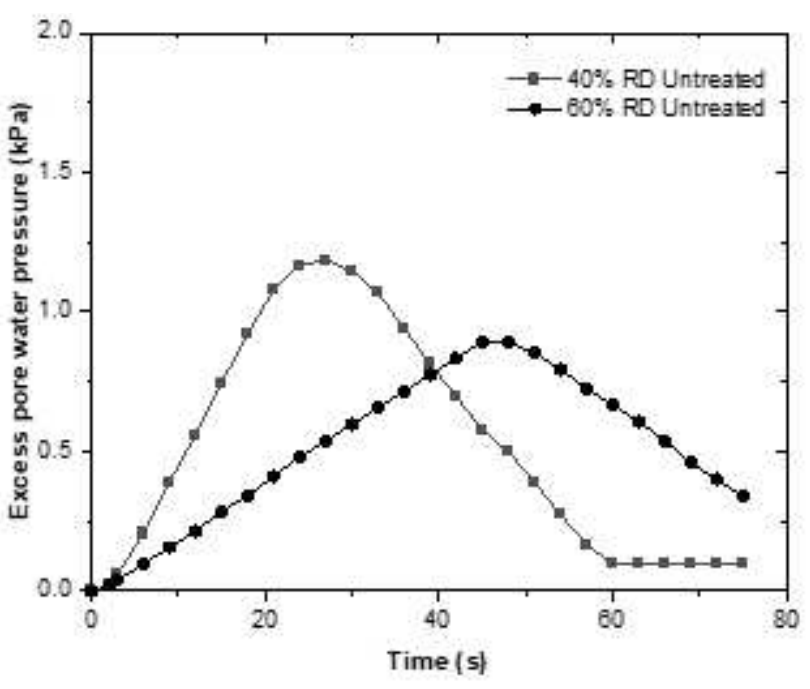

(a)

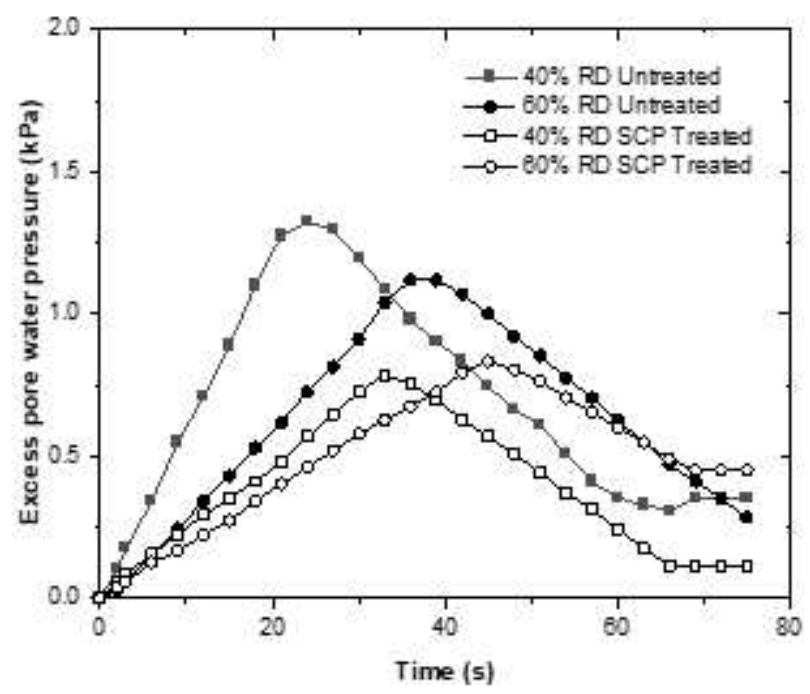

(b)

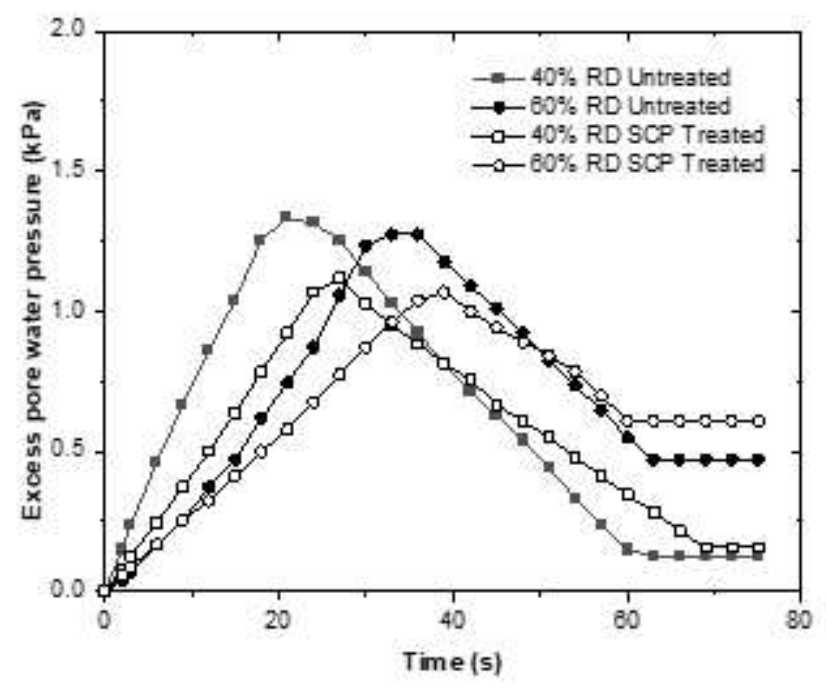

(c)

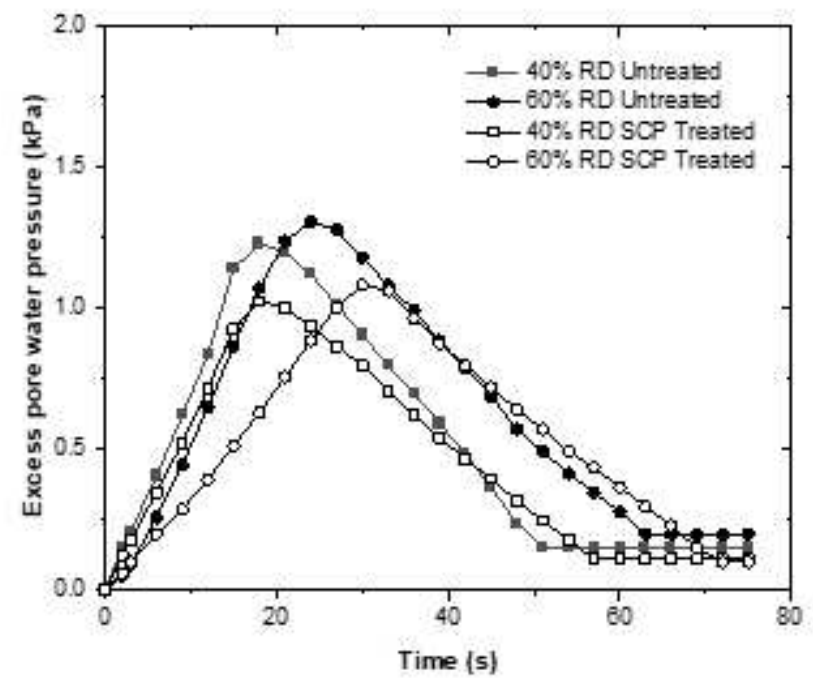

(d)

Figure 7

Time history of EPWP for treated and untreated soil conditions at top piezometer (a) $0.1 \mathrm{~g}$; (b) $0.2 \mathrm{~g}$; (c) $0.3 \mathrm{~g}$; (d) $0.4 \mathrm{~g}$. 


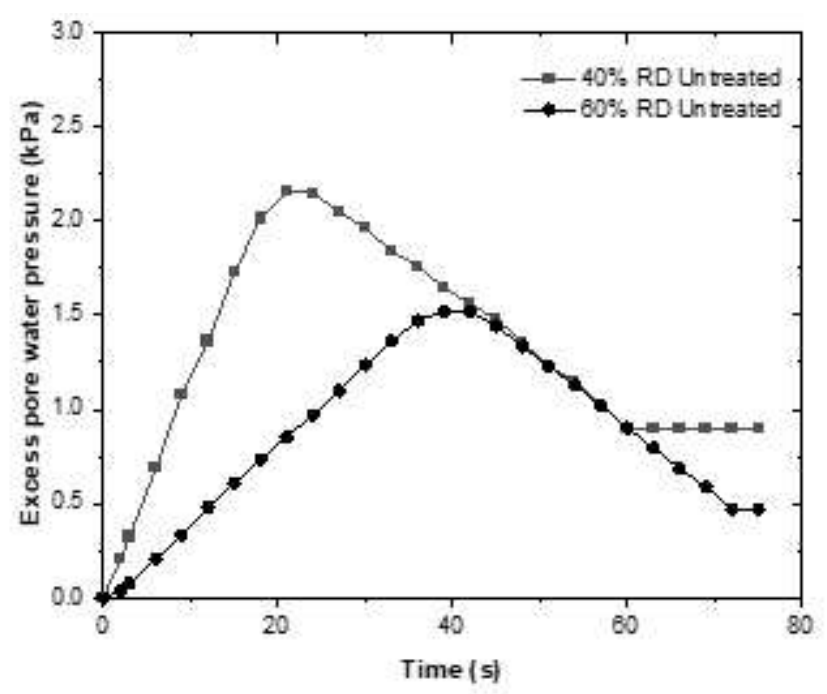

(a)

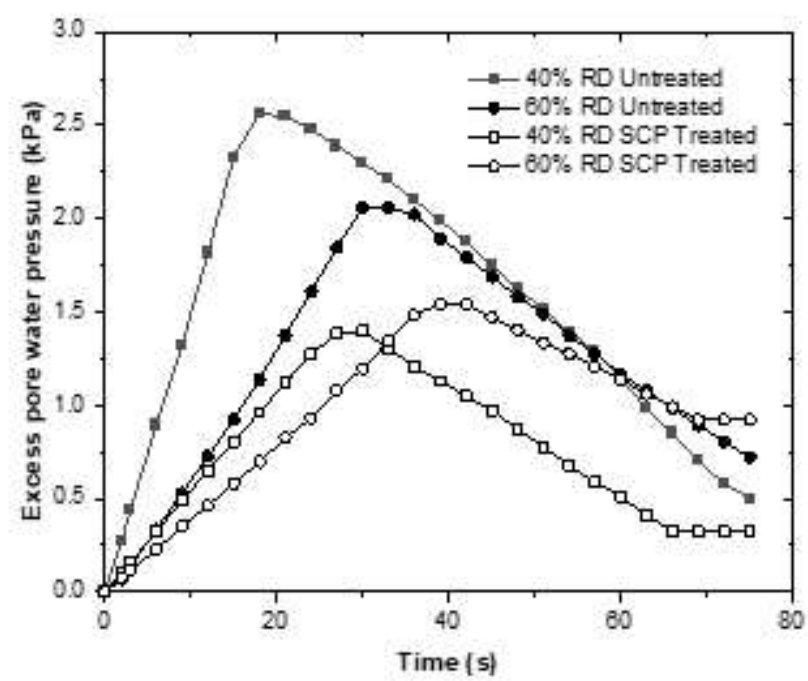

(b)

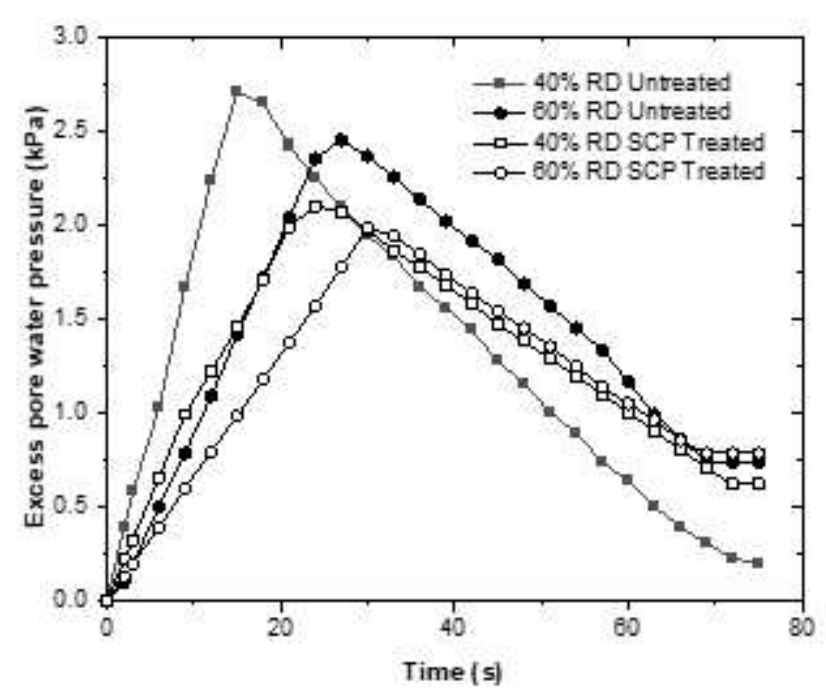

(c)

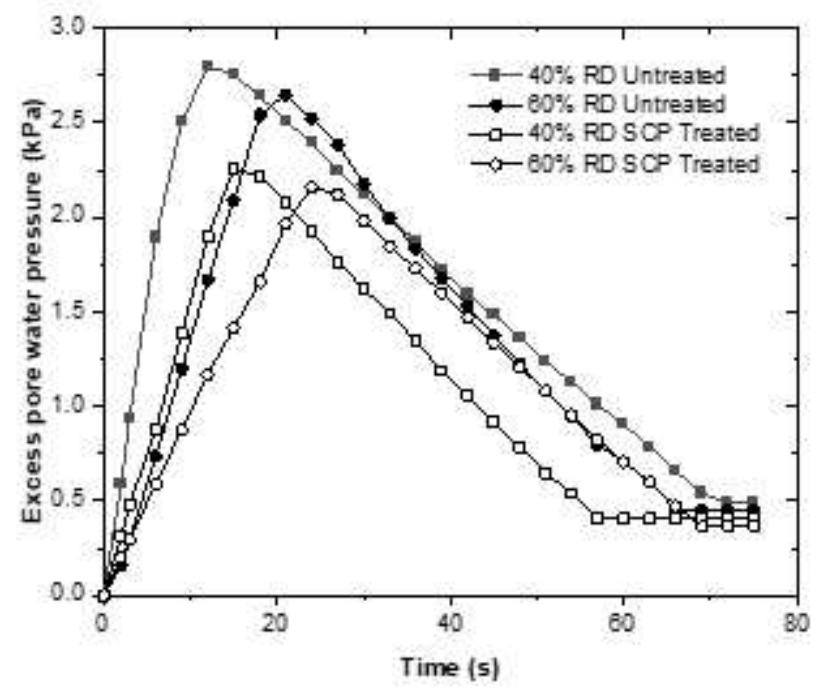

(d)

\section{Figure 8}

Time history of EPWP for treated and untreated soil conditions at bottom piezometer (a) $0.1 \mathrm{~g}$; (b) $0.2 \mathrm{~g}$; (c) $0.3 \mathrm{~g}$; (d) $0.4 \mathrm{~g}$. 


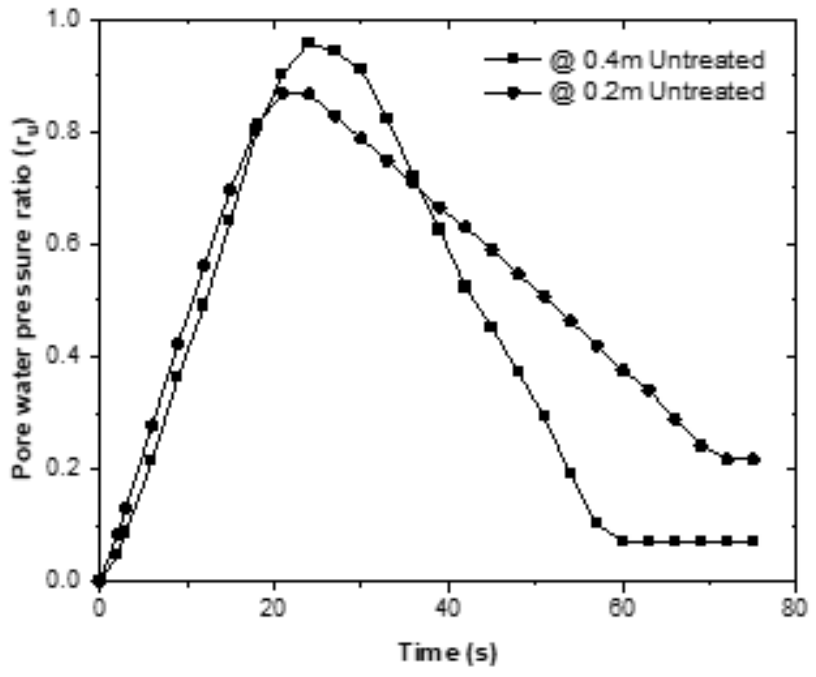

(a)

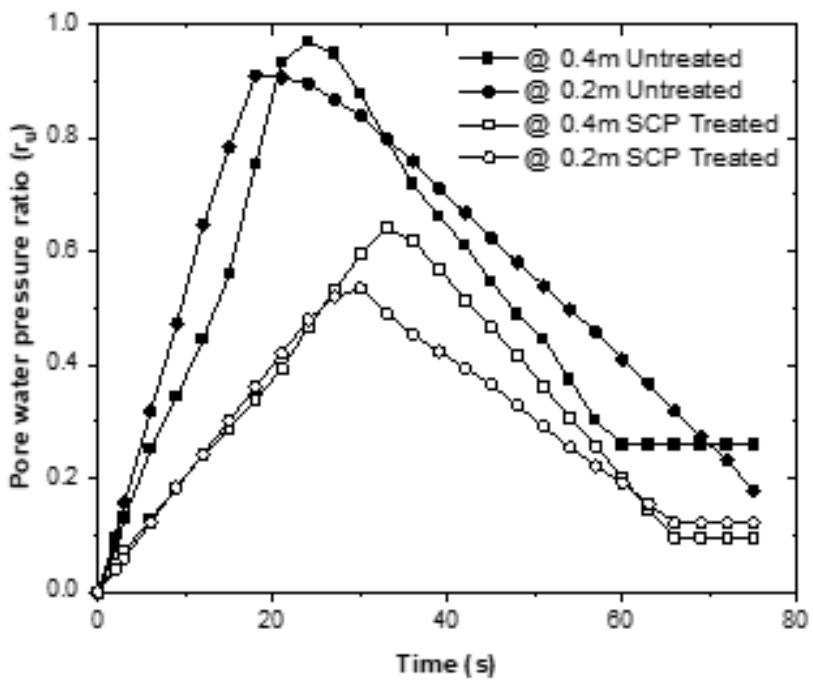

(b)

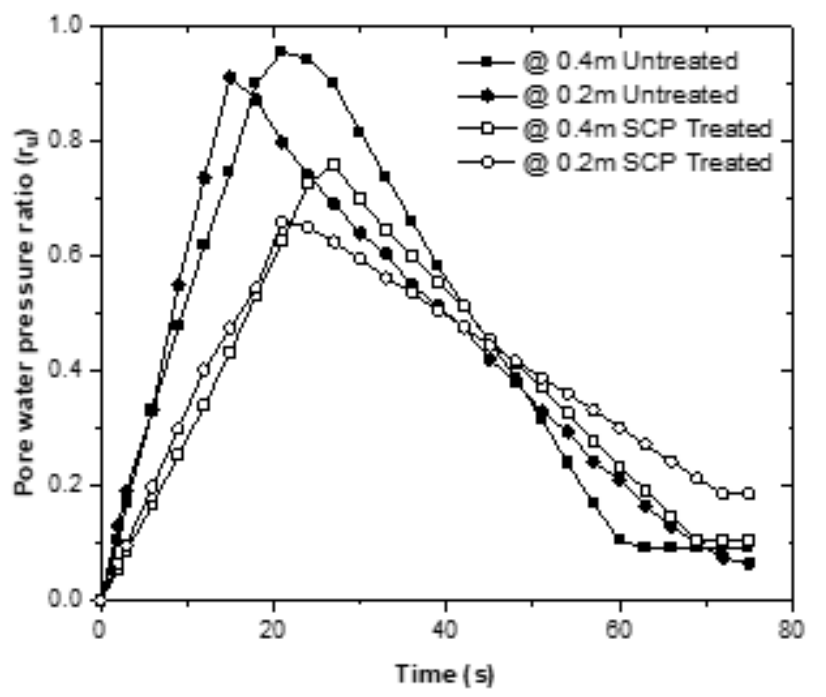

(c)

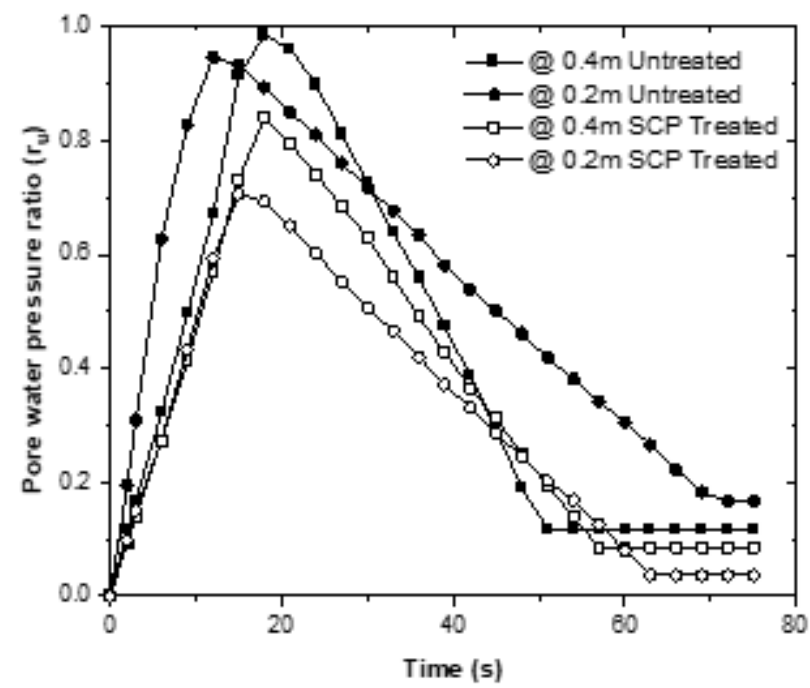

(d)

\section{Figure 9}

Time history of Pore water pressure ratio for SCP treated and untreated soil conditions for $40 \%$ relative density (a) $0.1 \mathrm{~g}$; (b) $0.2 \mathrm{~g}$; (c) $0.3 \mathrm{~g}$; (d) $0.4 \mathrm{~g}$. 


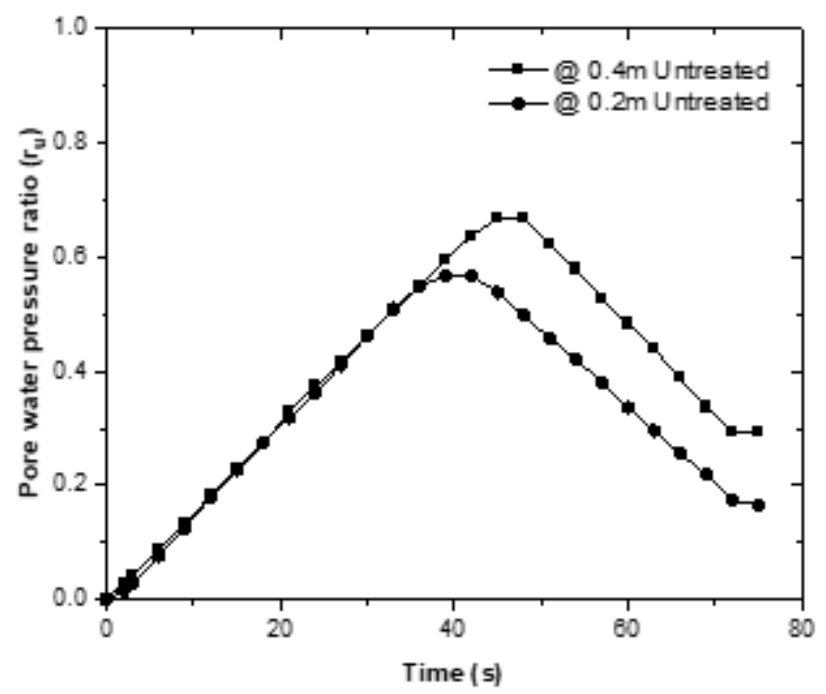

(a)

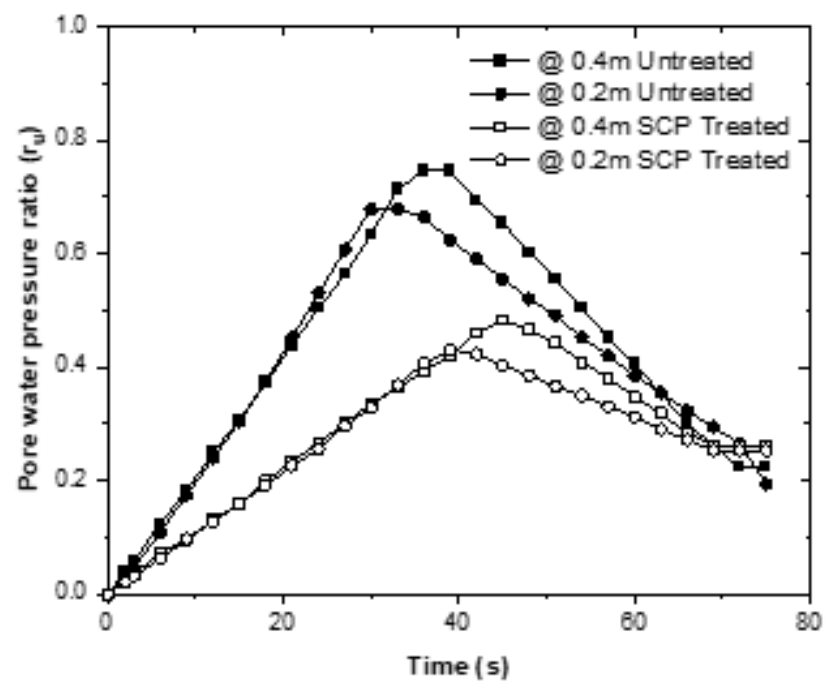

(b)

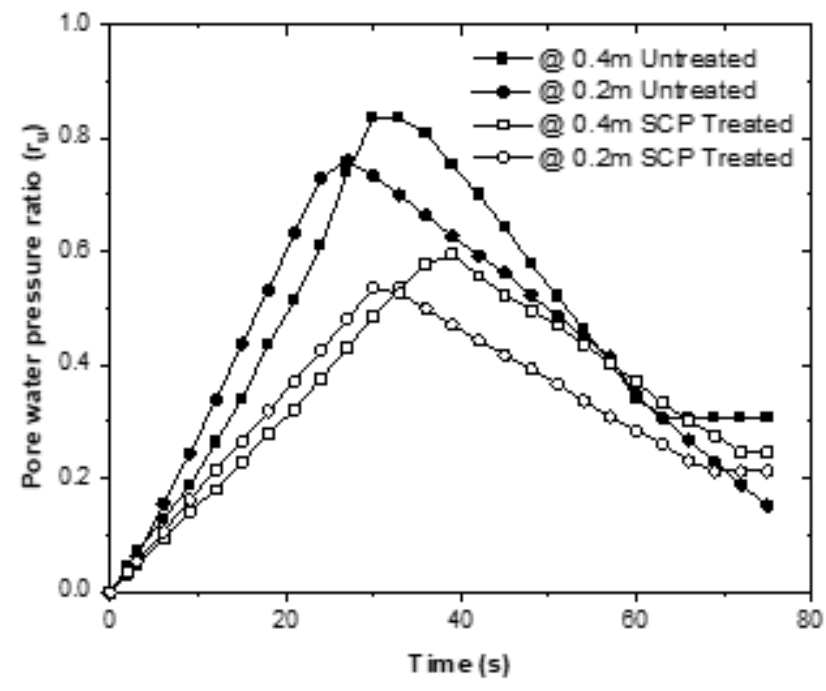

(c)

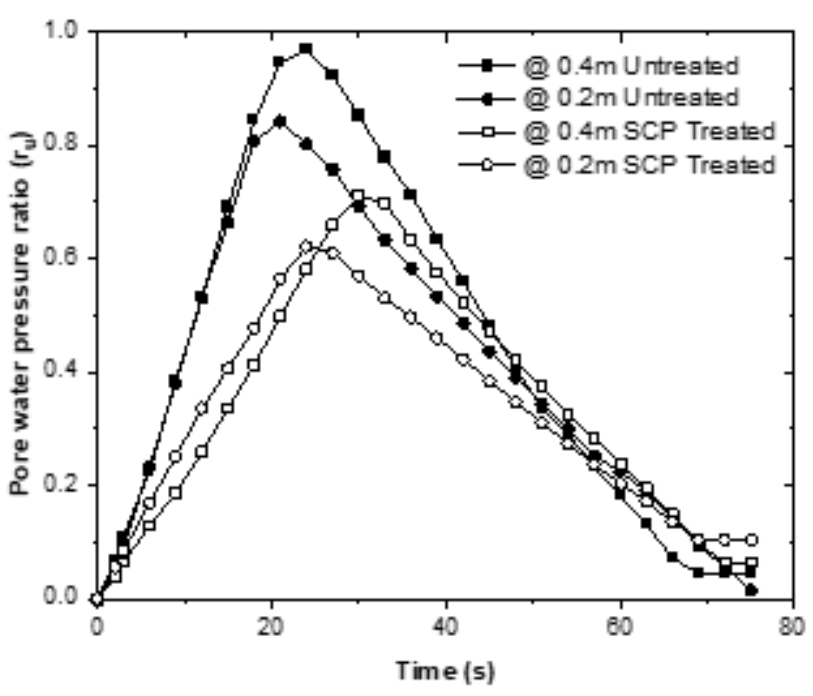

(d)

\section{Figure 10}

Time history of Pore water pressure ratio for SCP treated and untreated soil conditions for $60 \%$ relative density (a) $0.1 \mathrm{~g}$; (b) $0.2 \mathrm{~g}$; (c) $0.3 \mathrm{~g}$; (d) $0.4 \mathrm{~g}$. 


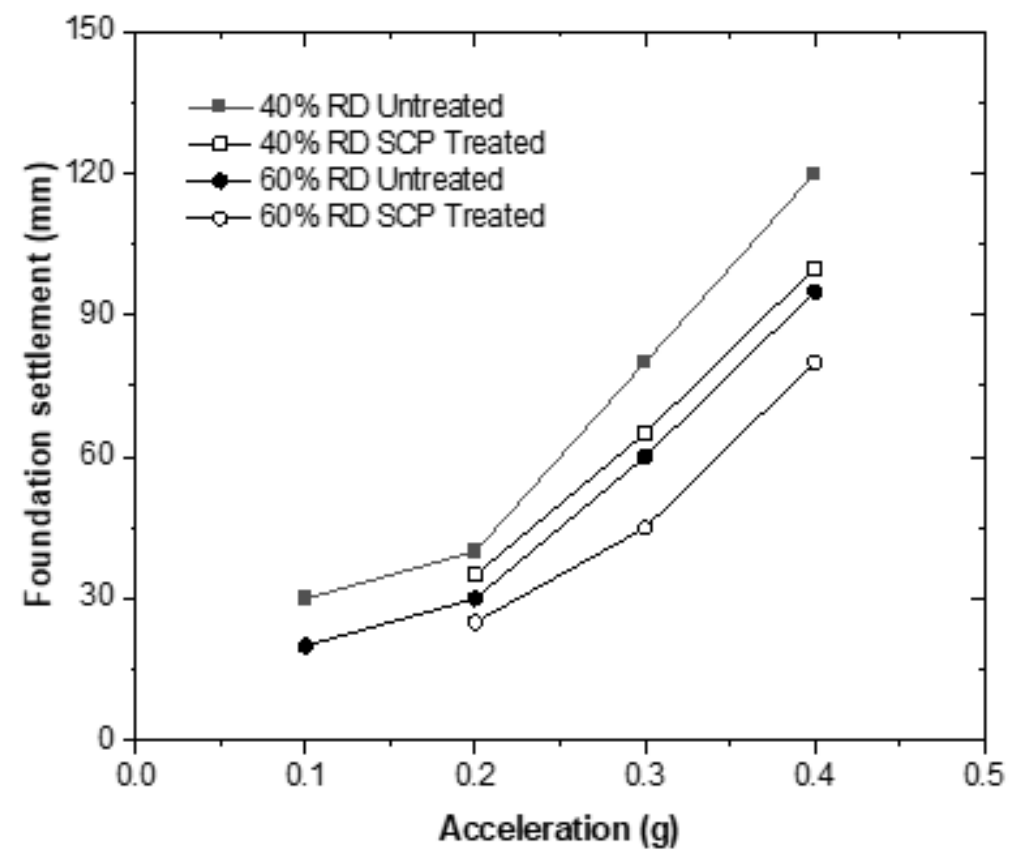

Figure 11

Foundation settlement at varying accelerations for $40 \%$ and $60 \%$ relative density (RD) for treated and untreated soil conditions. 


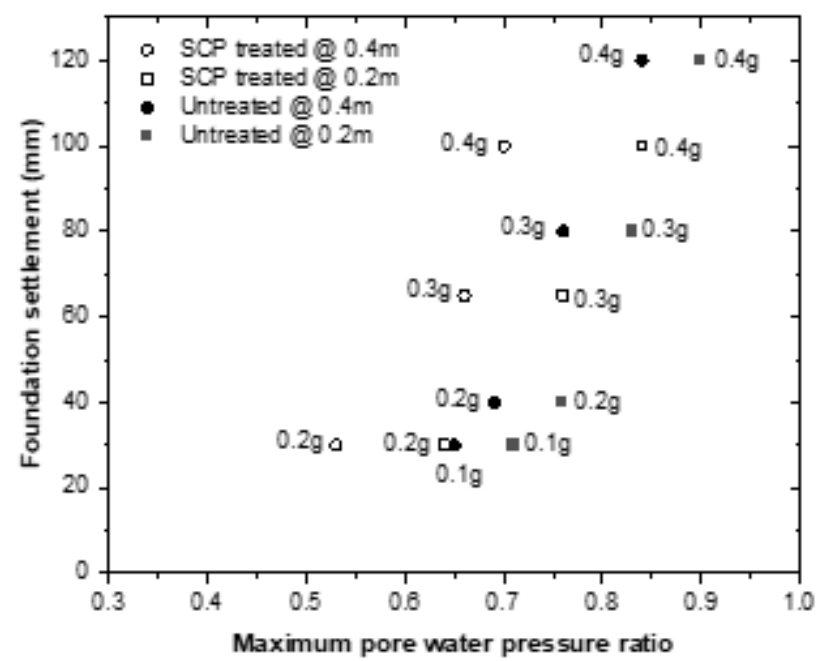

(a)

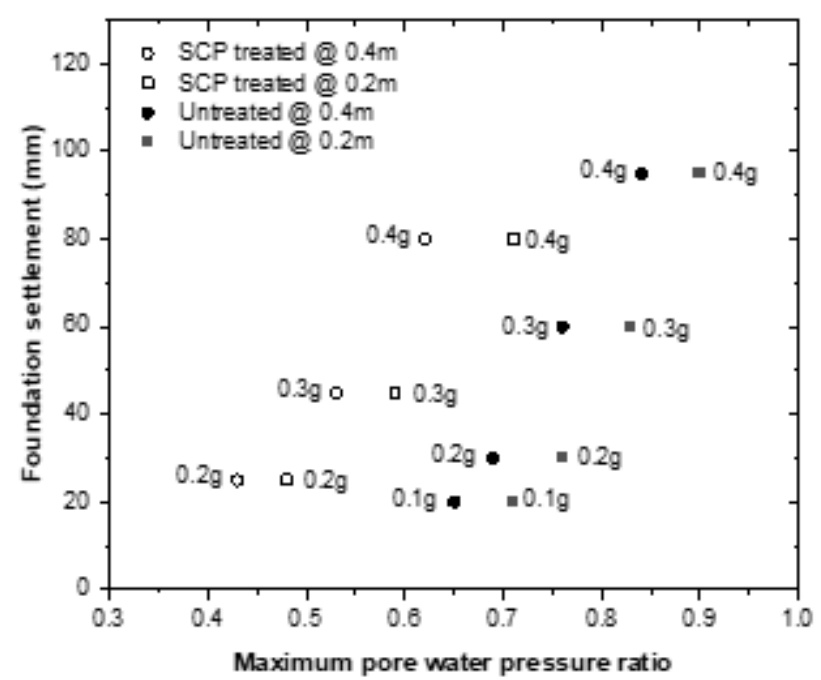

(b)

\section{Figure 12}

Untreated and treated foundation settlement versus maximum pore water pressure ratio (a) $40 \%$ relative density; (b) $60 \%$ relative density. 


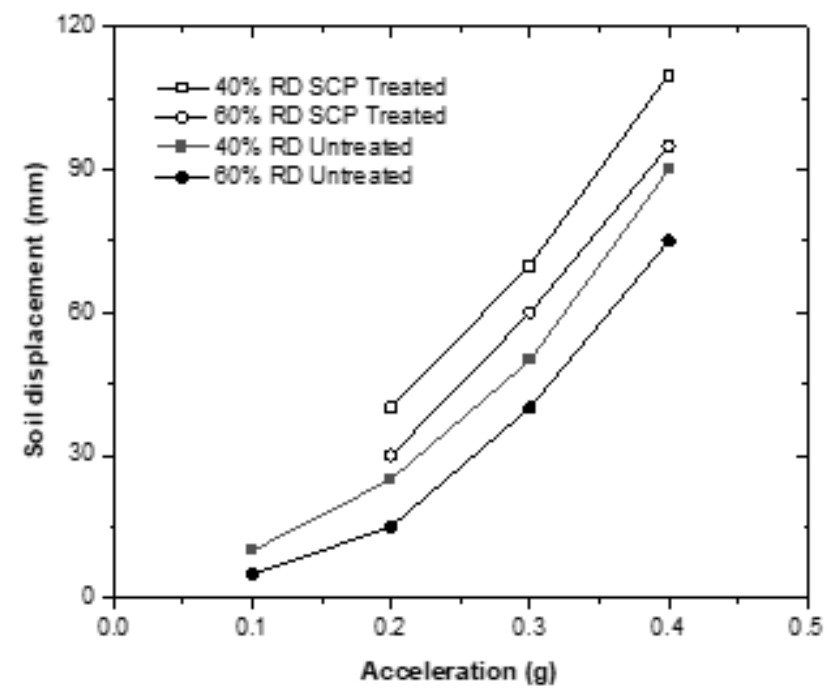

Figure 13

Surface soil displacement at varying accelerations for $40 \%$ and $60 \%$ relative density (RD) for treated and untreated soil conditions. 


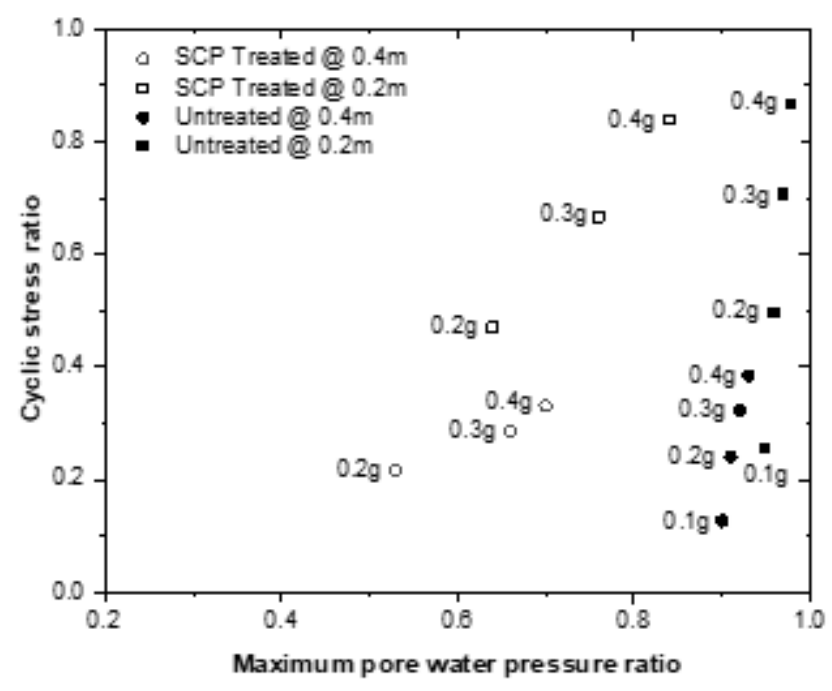

(a)

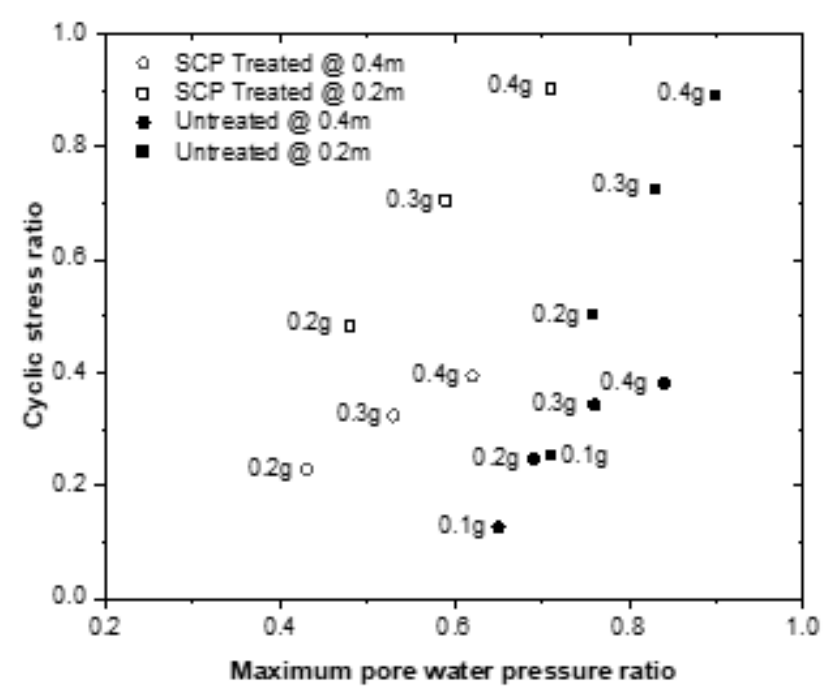

(b)

\section{Figure 14}

Untreated and treated cyclic stress ratio versus maximum pore water pressure ratio (a) $40 \%$ relative density; (b) $60 \%$ relative density. 


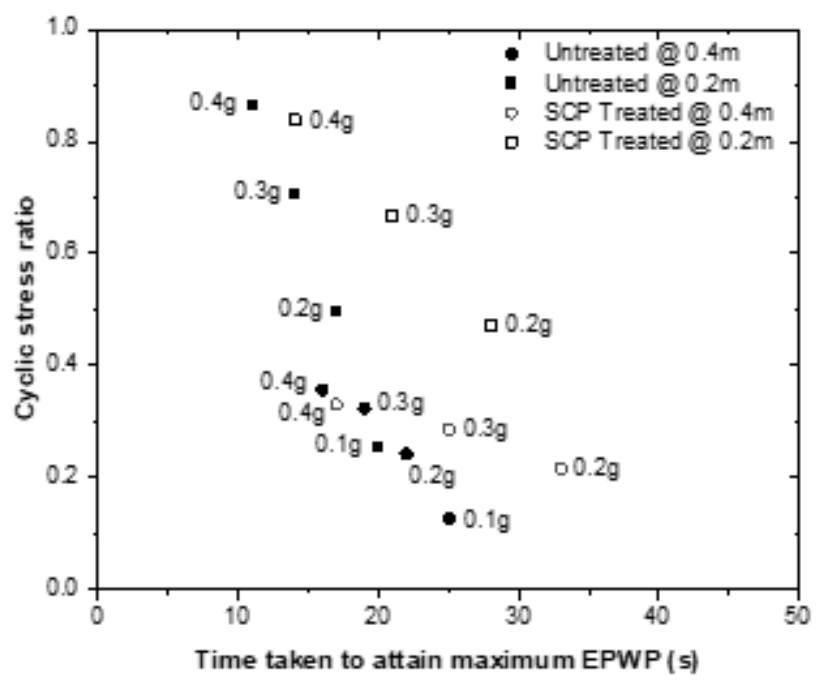

(a)

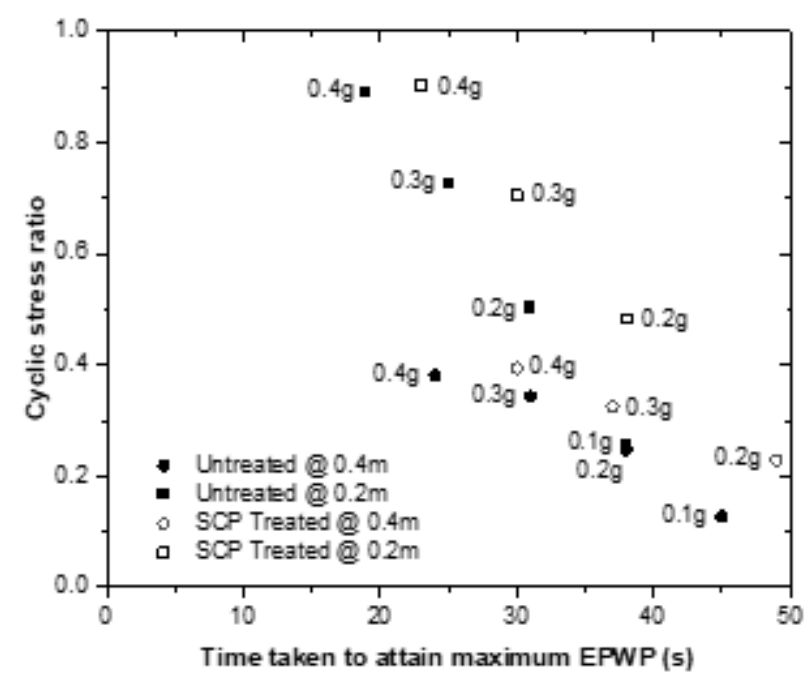

(b)

\section{Figure 15}

Untreated and treated cyclic stress ratio versus time taken to attain maximum EPWP (a) $40 \%$ relative density; (b) $60 \%$ relative density. 